\title{
The use of advanced medical technologies at home: a systematic review of the literature
}

\author{
Ingrid ten Haken ${ }^{1 *}$, Somaya Ben Allouch¹ and Wim H. van Harten ${ }^{2,3}$
}

\begin{abstract}
Background: The number of medical technologies used in home settings has increased substantially over the last 10-15 years. In order to manage their use and to guarantee quality and safety, data on usage trends and practical experiences are important. This paper presents a literature review on types, trends and experiences with the use of advanced medical technologies at home.

Methods: The study focused on advanced medical technologies that are part of the technical nursing process and 'hands on' processes by nurses, excluding information technology such as domotica. The systematic review of literature was performed by searching the databases MEDLINE, Scopus and Cinahl. We included papers from 2000 to 2015 and selected articles containing empirical material.

Results: The review identified 87 relevant articles, 62\% was published in the period 2011-2015. Of the included studies, 45\% considered devices for respiratory support, 39\% devices for dialysis and 29\% devices for oxygen therapy. Most research has been conducted on the topic 'user experiences' (36\%), mainly regarding patients or informal caregivers. Results show that nurses have a key role in supporting patients and family caregivers in the process of homecare with advanced medical technologies and in providing information for, and as a member of multi-disciplinary teams. However, relatively low numbers of articles were found studying nurses perspective.

Conclusions: Research on medical technologies used at home has increased considerably until 2015. Much is already known on topics, such as user experiences; safety, risks, incidents and complications; and design and technological development. We also identified a lack of research exploring the views of nurses with regard to medical technologies for homecare, such as user experiences of nurses with different technologies, training, instruction and education of nurses and human factors by nurses in risk management and patient safety.
\end{abstract}

Keywords: Home health nursing, Medical technologies, Patient safety, Quality of health care, Systematic review, Trends

\section{Background}

As a result of demographic changes and the rapidly increasing number of older patients, there is a need for cost savings and health reforms, which include an increased move from inpatient to outpatient care in most industrialized countries over the last 10-15 years [1,2]. As a consequence, the transfer of advanced medical devices into home settings was considerable and it is expected that there will be a further increase in the near future [1-7].

\footnotetext{
* Correspondence: i.tenhaken@saxion.nl

'Saxion University of Applied Sciences, Research Group Technology, Health \& Care (TH\&C), P.O. Box 70.000, 7500 KB Enschede, The Netherlands

Full list of author information is available at the end of the article
}

When 'an increase' in the number of medical technologies used at home is mentioned, it is not clear which and how many technologies are involved. Today, there are an estimated 500,000 different kinds and types of medical devices available on the world market $[8,9]$. The European Commission (EC) publishes data regarding legislation and regulations for medical devices, but the actual figures for medical technologies in outpatient practice are not available [10]. The U.S. National Center for Health Statistics (NCHS) stated that technologies have shifted from hospitals into the home, but it too does not illustrate its findings with statistics [11]. We searched for data with regard to the actual number of 
medical technologies used in home settings and it proved difficult to find any systematic data sets available throughout the international landscape.

An important condition for the application of medical technology in the home setting is that quality of care and patient safety must be guaranteed [6]. From a historical perspective medical technologies were designed for hospital settings $[12,13]$. This means that specific factors regarding the implementation and use at home now need to be taken into account $[7,14,15]$. In general, risks with medical technologies can be classified regarding (a) environmental factors; (b) human factors and (c) technological factors [16]. Human factors, however, are very important in patient safety in both hospital and in home settings $[1,6,12]$. For example, a major risk factor is the number of users and handovers in the chain of care. In home settings, a sometimes impressive number of different users of medical technology, often with various levels of training, instruction or education, are involved. Although patient empowerment moves control to the patient and/or relatives, an important user group is that of professional nurses. Understanding user experiences and information about adverse events and near incidents are important aspects for developing knowledge regarding implementation and use in home care setting. Sharing this knowledge can support patients and caregivers, and especially nurses in their professional work and will also contribute to patient safety and quality of care.

Therefore, there is a need to address the question first, which types of technologies are used at home; second, how frequently are they used and third, what trends can be distinguished. Additional research questions are whether there are any scientific data regarding particular user experiences; training, instruction and education; safety and risks, and finally, what can be concluded about the role of nurses in using medical technologies in the home environment. The objective of this paper therefore is to present a systematic literature search on the international state of art concerning various aspects of the use of advanced medical technologies at home.

\section{Definitions}

First, we want to clarify some definitions. In general, 'health technology' refers to the application of organized knowledge and skills in the form of devices, medicines, vaccines, procedures and systems developed to solve a health problem and improve quality of life [17]. The World Health Organization [8] uses the definition of 'medical device' as 'An article, instrument, apparatus or machine that is used in the prevention, diagnosis or treatment of illness or disease, or for detecting, measuring, restoring, correcting or modifying the structure or function of the body for some health purpose ........ A specification for a home use medical device is: 'A medical device intended for users in any environment outside of a professional healthcare facility. This includes devices intended for use in both professional healthcare facilities and homes' [18].

The landscape of medical devices is diverse with technologies varying from relatively simple to very complex devices. Wagner et al. [19] stated that 'high-tech dependency' (for children) matches with 'technology-dependency' if it concerns 'a medical device to compensate for the loss of a vital bodily function and substantial and ongoing nursing care to avert death or further disability'. 'The needs of these patients may vary from the continuous assistance of a device and highly trained caretaker to less frequent treatment and intermittent nursing care' [20]. Although patients dependent of advanced medical technologies at home are often medically stable, they sometimes have high technical needs and may be expected to need long-term recovery. They also require skilled nursing [21] and a considerable degree of advanced decision making, planning, training and oversight [22]. An overall definition of 'advanced medical technology' is: 'Medical devices and software systems that are complex, provide critical patient data, or that directly implement pharmacologic or life-support processes whereby inadvertent misuse or use error could present a known probability of patient harm' [23]. Examples of advanced medical technologies used at home include ventilators for respiratory support, systems for haemo- or peritoneal dialysis and infusion pumps to provide nutrition or medication.

In the Netherlands, the National Institute for Public Health and the Environment (RIVM) [24] uses the following definition:

Advanced medical technology or high-tech technology in the home setting is defined as technology that is part of the technical skills in nursing and meets the following conditions:

- technology that is advanced or high-tech, for example equipment with a plug, an on/off switch, an alarm button and a pause button;

- technology that had been applied formerly only in hospital care, but that is now also often applied in home settings;

- technology that can be categorized as 'supporting physiological functions', 'administration' or 'monitoring'.

Within the Dutch classification of advanced medical technologies 19 different devices are identified (see Table 1), which will be used in this review as a basis to categorize the technologies. It is a classification format in which specific advanced technologies are defined. 
Table 1 Classification of advanced medical technologies in the Netherlands according to the National Institute for Public Health and the Environment (RIVM) [24]

\begin{tabular}{l}
\hline Technologies with regard to: \\
\hline Supporting physiological functions: \\
1. Respiratory support \\
2. Sleep apnea treatment \\
3. Suction devices \\
4. Oxygen therapy \\
5. Dialysis \\
6. Vacuum assisted wound closure \\
7. Decubitus treatment \\
8. External electrostimulation \\
9. Continuous passive motion \\
10. Skeletal traction \\
11. Patient lifting hoists \\
Administration: \\
12. Infusion therapy \\
13. Insulin pump therapy \\
14. Parenteral nutrition \\
15. Enteral nutrition \\
16. UV therapy \\
17. Nebulizer \\
18. Fetal cardiotocography \\
19. Respiratory and circulatory monitoring
\end{tabular}

Terms as 'advanced medical technology' (from now on abbreviated as AMT) will be used consistently as synonyms for 'complex medical technology' and 'high-tech medical technology'. The term 'technology' will be used in the meaning of 'device' or 'equipment'. The target is on technologies that are instrumental and 'hands on' use by nurses in the care for patients. This means that information technology (IT) based technologies as domotica (automation for a home) are not part of the study.

\section{Methods}

\section{Eligibility and search strategy}

The systematic review of the literature was conducted early 2016. Key concepts for the review were 'medical technologies' or 'medical devices', and 'home settings'. The concept of 'home settings' is related to the terms 'home nursing' and 'home care service', of which the stem is 'home'. Combining the key concepts provided the search string: ('medical technology' OR 'medical device'). As domotica is not part of the study, the search string was extended with: AND NOT (eHealth OR telecare OR telemedicine). The exact search string is ("medical technology" OR "medical devices") AND home
AND NOT (ehealth OR telecare OR telemedicine). Online databases MEDLINE, Scopus and Cinahl were searched electronically using the search string to obtain data.

\section{Inclusion and exclusion criteria}

Criteria for selection were defined prior to the search process. General criteria for inclusion were:

- Year of publication: 2000-2015.

- An abstract or an article (with or without abstract) has to be available, containing reference to AMT information.

- The article is published in English, German, French or Dutch/Flemish language.

- If medical technology is cited, it has to conform to the definition of 'advanced medical technology' [24].

- The abstract or the article has to contain empirical material. For the purpose of this review, 'empirical material' has been defined as: AMT which is designed for the home setting, or where the design or choices took into account the setting of the home, or where the medical technology has been tested for the home or if the medical technology is already on the market and being used in the home setting.

For further selection, inclusion criteria related to the key concepts for title and abstract were applied, such as 'advanced medical technology', 'high-tech medical technology', 'home-centred health-enabling technology' and 'care at home'. The classification of the RIVM (see Table 1) has been taken as a basis to categorize technologies in this review. Domotica and telemonitoring technologies scored under 'monitoring', such as fetal cardiotocography, and respiratory and circulatory monitoring, were left out. If the abstract or article was about electronic health records, 'smart home', ambient intelligence, pervasive computing, software of devices, smartphone or surgical robots, the article was also removed from selection. Technologies as 'VAD (ventricular assist device)', 'dental devices' and 'AED (automatic external defibrillator)' were not seen as part of the technical nursing process and these records were left out as well. Studies conducted in the hospital, hospice or nursing home settings were also excluded. An overview of all inclusion and exclusion criteria can be found in Table 2.

\section{Screening process}

The search in the online databases using the search string, identified a total of 1287 references. After checking for duplicates, 1070 articles remained. Those articles were reviewed by a reviewer for titles and abstracts on basis of the inclusion and exclusion criteria. A double check was performed by two reviewers, who 
Table 2 Inclusion and exclusion criteria for title and abstract and/or

\begin{tabular}{|c|c|c|}
\hline & Inclusion & Exclusion \\
\hline Title & $\begin{array}{l}\text { Advanced medical } \\
\text { technology (-ies) } \\
\text { Medical technology (-ies) } \\
\text { Medical device(s) } \\
\text { High-tech medical } \\
\text { technology (-ies) } \\
\text { High-tech home care } \\
\text { Home } \\
\text { Homecare } \\
\text { Home health care } \\
\text { Home-based care } \\
\text { Home-based } \\
\text { technology (-ies) } \\
\text { Home-centered health- } \\
\text { enabling technology (-ies) } \\
\text { Care at home } \\
\text { Care in the home } \\
\text { AND } \\
\text { Inclusion criteria for abstract } \\
\text { below }\end{array}$ & $\begin{array}{l}\text { eHealth } \\
\text { Telehealth } \\
\text { Telenursing } \\
\text { Telemedicine } \\
\text { Telemedical system } \\
\text { Telehomecare } \\
\text { Telecare } \\
\text { Teleconsultation } \\
\text { Ambient assisted } \\
\text { environment } \\
\text { iPad technology } \\
\text { VAD (ventricular assist } \\
\text { device) } \\
\text { Dental devices } \\
\text { ECG (electrocardiogram) } \\
\text { AED (automatic external } \\
\text { defibrillator) } \\
\text { Hospital } \\
\text { Hospice } \\
\text { Nursing home }\end{array}$ \\
\hline $\begin{array}{l}\text { ostract } \\
\text { Id/or } \\
\text { ticle }\end{array}$ & $\begin{array}{l}\text { Year of publication: 2000-2015 } \\
\text { 1. Respiratory support (RIVM) } \\
\text { Respirator } \\
\text { Respiratory support } \\
\text { Respiratory therapy } \\
\text { Ventilator } \\
\text { Ventilator-assisted } \\
\text { Mechanical ventilation } \\
\text { Support ventilation } \\
\text { Invasive ventilation } \\
\text { Non-invasive ventilation } \\
\text { Non-invasive mechanical } \\
\text { ventilation } \\
\text { Continuous positive } \\
\text { airway pressure (CPAP) } \\
\text { Bilevel positive airway } \\
\text { pressure (BPAP, BiPAP) } \\
\text { Negative pressure } \\
\text { ventilation (NVP) } \\
\text { Mechanical in-exsufflation } \\
\text { 2. Sleep apnea treatment (RIVM) } \\
\text { Sleep apnea treatment device } \\
\text { (Positive) airway pressure } \\
\text { device (PAP) } \\
\text { 3. Suction devices (RIVM) } \\
\text { Suction machine } \\
\text { Suction apparatus } \\
\text { Airway suction device } \\
\text { Digital suction } \\
\text { Mucus removal } \\
\text { 4. Oxygen therapy (RIVM) } \\
\text { Oxygen therapy } \\
\text { Long-term oxygen cylinder } \\
\text { Long-term oxygen ventilator } \\
\text { Supplemental oxygen } \\
\text { Oxygen conserver } \\
\text { Oxygen concentrator } \\
\text { Oxygen tank } \\
\text { 5. Dialysis (RIVM) } \\
\text { Haemo dialysis } \\
\text { Hemo dialysis } \\
\text { Peritoneal dialysis } \\
\text { Peritoneal catheter } \\
\text { drainage system } \\
\text { Peritoneal automatic } \\
\text { delivery system } \\
\text { Men }\end{array}$ & $\begin{array}{l}\text { - If no abstract and no } \\
\text { article available } \\
\text { - If the title is in English, } \\
\text { but the article is written } \\
\text { not in English, German, } \\
\text { French or Dutch/ Flemish. } \\
\text { - If about medical } \\
\text { technologies, but not } \\
\text { about the application in } \\
\text { the setting of the home. } \\
\text { - If the abstract or article } \\
\text { contains no empirical } \\
\text { material. For the purpose } \\
\text { of this review, 'empirical } \\
\text { material' is defined as: } \\
\text { - medical technology } \\
\text { which is designed for } \\
\text { the home setting, or } \\
\text { - where the design or } \\
\text { choices took into } \\
\text { account the setting of } \\
\text { the home, or } \\
\text { - where the medical } \\
\text { technology has been } \\
\text { tested for the home and } \\
\text { - if the medical } \\
\text { technology is already on } \\
\text { the market or being used } \\
\text { in the home setting. } \\
\text { - If the abstract or article } \\
\text { is about: } \\
\text { - electronic health records } \\
\text { - 'smart home' } \\
\text { - ambient intelligence } \\
\text { - pervasive computing } \\
\text { - software of devices } \\
\text { - smart phone } \\
\text { - (surgical) robots } \\
\text { - If not conform the } \\
\text { definition of RIVM ( } 2013, \\
\text { page } 15 \text { ) of 'complex } \\
\text { medical technology'. } \\
\text { Advanced medical } \\
\text { technology or high-tech } \\
\text { technology in the home } \\
\text { setting is defined as }\end{array}$ \\
\hline
\end{tabular}

Table 2 Inclusion and exclusion criteria for title and abstract and/or (Continued)

\begin{tabular}{cl}
\hline Inclusion & Exclusion \\
\hline CAPD (Continuous Ambulatory & technology that is part of \\
Peritoneal Dialysis) & the technical skills in \\
APD (Automated & nursing and meets the \\
Peritoneal Dialysis) & following conditions: \\
Dialysis machine & - technology that is \\
Sorbent dialysis & advanced or high-tech, i.e. \\
6. Vacuum assisted wound & equipment with a plug, a \\
closure (RIVM) & switch on/off button, alarm \\
Negative-pressure wound & button, pause button etc.; \\
therapy system & - technology that had been \\
VAC- therapy & applied formerly in hospital \\
NPWT & care ('intramural'), but that \\
Vacuum assisted wound & is applied also often in \\
closure & home settings nowadays; \\
7. Decubitus treatment (RIVM) & - technology that can be \\
Pressure ulcer treatment & categorized as 'supporting \\
Decubitus treatment & physiological functions', \\
Decubitus mattress & 'administration' or \\
Pressure relief mattress & 'monitoring'.
\end{tabular}

8. External electrostimulation (RIVM)

(External) electrostimulation Electrical stimulation TENS

Nerve stimulation Transcutaneaous electrical stimulation to treat slow-transit constipation

9. Continuous passive motion (RIVM)

Continuous passive motion Motion therapy

10.Skeletal traction (RIVM)

(Skeletal) traction Tension

11.Patient lifting hoists (RIVM) Patient lift Patient hoist Transfer device

12. Infusion therapy (RIVM) Infusion pump Infusion therapy Central venous catheter Central venous line Port a cath PICC (perifally inserted central catheter) Intravenous medication Intravenous therapy Intravenous chemotherapy Analgesia pump PCA-pump (patient controlled analgesia pump) Indwelling venous catheter

13. Insulin pump therapy (RIVM) Insulin pump therapy Insulin infusion

14. Parenteral nutrition (RIVM) Parenteral nutrition Parenteral feeding Intravenous nutrition

15. Enteral nutrition (RIVM) Enteral nutrition Tube feeding / feeding tube Feeding pump Enteral feeding 
Table 2 Inclusion and exclusion criteria for title and abstract and/or (Continued)

\begin{tabular}{cc}
\hline Inclusion & Exclusion \\
\hline PEG-tube (percutaneous & \\
endoscopic gastrostomy) & \\
PEGJ-tube (percutaneous & 18. Fetal cardiotocography \\
endoscopic gastrostomy, & (RIVM) \\
jejeunum) & Electronic fetal \\
Percutaneous gastrostomy & monitoring \\
tube & Fetal monitoring \\
Jejeunostomy tube & Cardiotocography \\
Gastrostomy feeding & 19. Respiratory and \\
16. UV therapy (RIVM) & circulatory monitoring \\
UV therapy & (RIVM) \\
Ultraviolet therapy & Capnography \\
Phototherapy & Respiratory monitoring \\
17. Nebulizer (RIVM) & Circulatory monitoring \\
Nebulizer & Pulse oximeter \\
& Electrocardiography \\
\hline
\end{tabular}

independently screened random samples of $20 \%$ of the articles. There was an initial agreement of $88 \%$. In case of disagreement about the inclusion of an article, the decision was based on a joint discussion by all three reviewers to an agreement of $100 \%$ and the resulting screening policy was applied to the rest of the abstracts. Based on the selected titles and/or abstracts, articles were retrieved or requested in full text and assessed for eligibility. Some articles were excluded from further study, for reasons of 'full text not available' or the article contained no empirical material. Finally, 87 studies remained which were included in the analysis (see Table 3). A graphical representation of the screening process has been included in Fig. 1.

\section{Appraisal of selected studies}

To conduct the systematic literature search on the international state of art concerning various aspects of the use of advanced medical technologies at home, several sources are consulted. To guarantee a scientific standard, only articles were retrieved from academic databases. MEDLINE refers to journals for biomedical literature from around the world; Cinahl contains an index of nursing and research journals covering nursing, biomedicine, health sciences librarianship, alternative medicine, allied health and more. These databases related to discipline have been supplemented with Scopus, which is considered to be the largest abstract and citation database of peer-reviewed literature. Grey literature, such as national and international reports on regulations and safety of medical technologies, is also used to illustrate the background of the problem statement and describe definitions. The Classification of advanced medical technologies in the Netherlands according to the National Institute for Public Health and the Environment (RIVM) has been used as a framework to categorise the medical technologies in the selected articles. No methodological conditions of selected studies were applied in advance and the quality criterion we applied was that of the article had to contain empirical material, as we wanted to obtain an comprehensive overview of published studies of any design and to get insight in a variety of contents.

\section{Results \\ Categorization of included articles}

The characteristics of the included articles are outlined in Table 3. All included articles were categorized by year of publication and the type of research, like the designs, methods and used instruments in the studies. Research features were synthesized where possible into overarching categories. For example, 'systematic review' and 'narrative review' were scored as 'review' and instruments as 'semi-structured interview' and 'in-depth individual interview' were both assigned to the category 'interview'.

For each study, the medical technology or technologies on which the study was based was scored. The categorization was in accordance with the classification of AMTs (see Table 1). For example, the devices 'continuous positive airway pressure (CPAP)' and 'negative pressure ventilation (NPV) have both been categorized as 'respiratory support'; and the devices 'jejeunostomy tube' and 'gastronomy tube' as 'enteral nutrition'. With regard to the category 'dialysis', further subdivision was made by using 'haemo dialysis' and 'peritoneal dialysis'. If in an article a medical technology was mentioned as an example, but was no subject of study, then the technology was not scored.

'Medical diagnosis (or diagnoses)' as mentioned in the studies, was included in the analysis only if it was related to the medical technology as the subject of study, not if it has been mentioned as an example. In some cases, an underlying cause of diagnosis was indicated. For example, 'chronic respiratory failure due to congenital myopathy', in itself a neurological disorder, has been scored as 'neurological disorder'. Diseases or disorders have been classified as much as possible under the overarching name. For example 'pneumonia' and 'cystic fibrosis' are categorized under 'respiratory failure', and 'gastroparesis' and 'Crohns disease' under 'gastrointestinal disorder'. The category 'other' contains diagnoses which occur only once, such as 'chromosomal anomaly', or which are not yet determined, like 'chronic diseases' or 'congenital abnormalities'.

In relation to the research questions, articles were classified regarding one of the following categories and, where appropriate, into subcategories:

1. User experiences

2. Training, instruction and education

3. Safety, risks, incidents and complications 


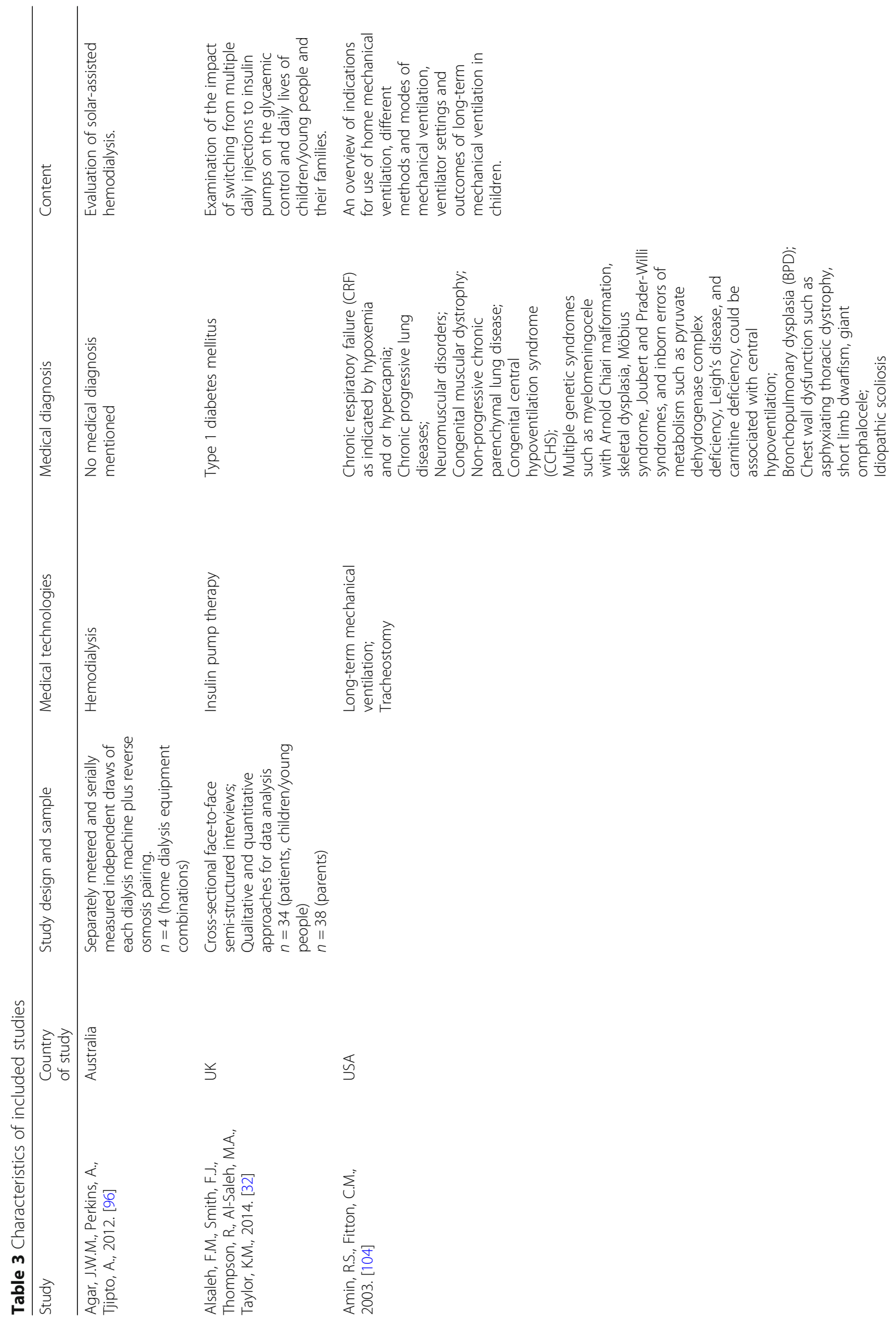




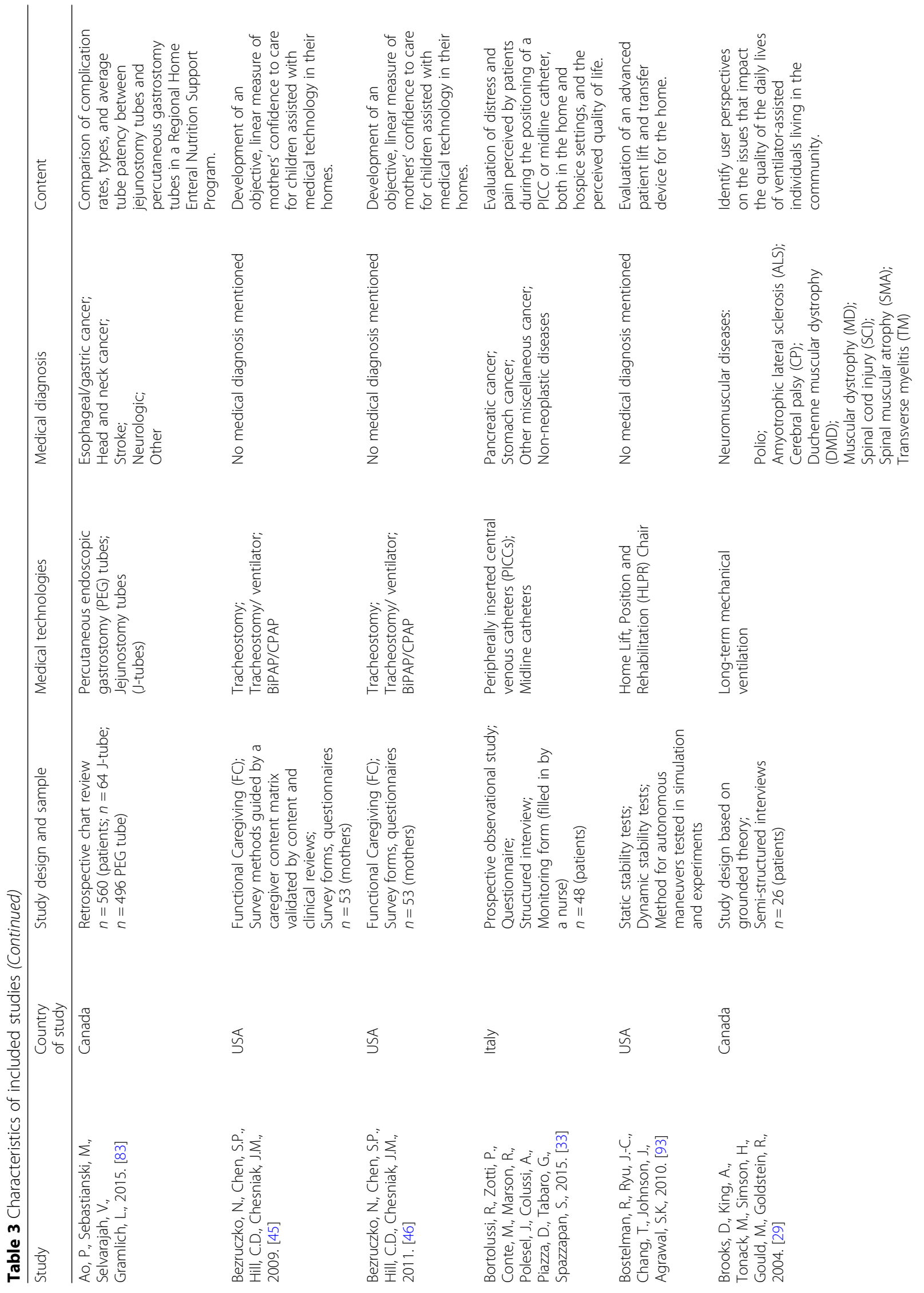




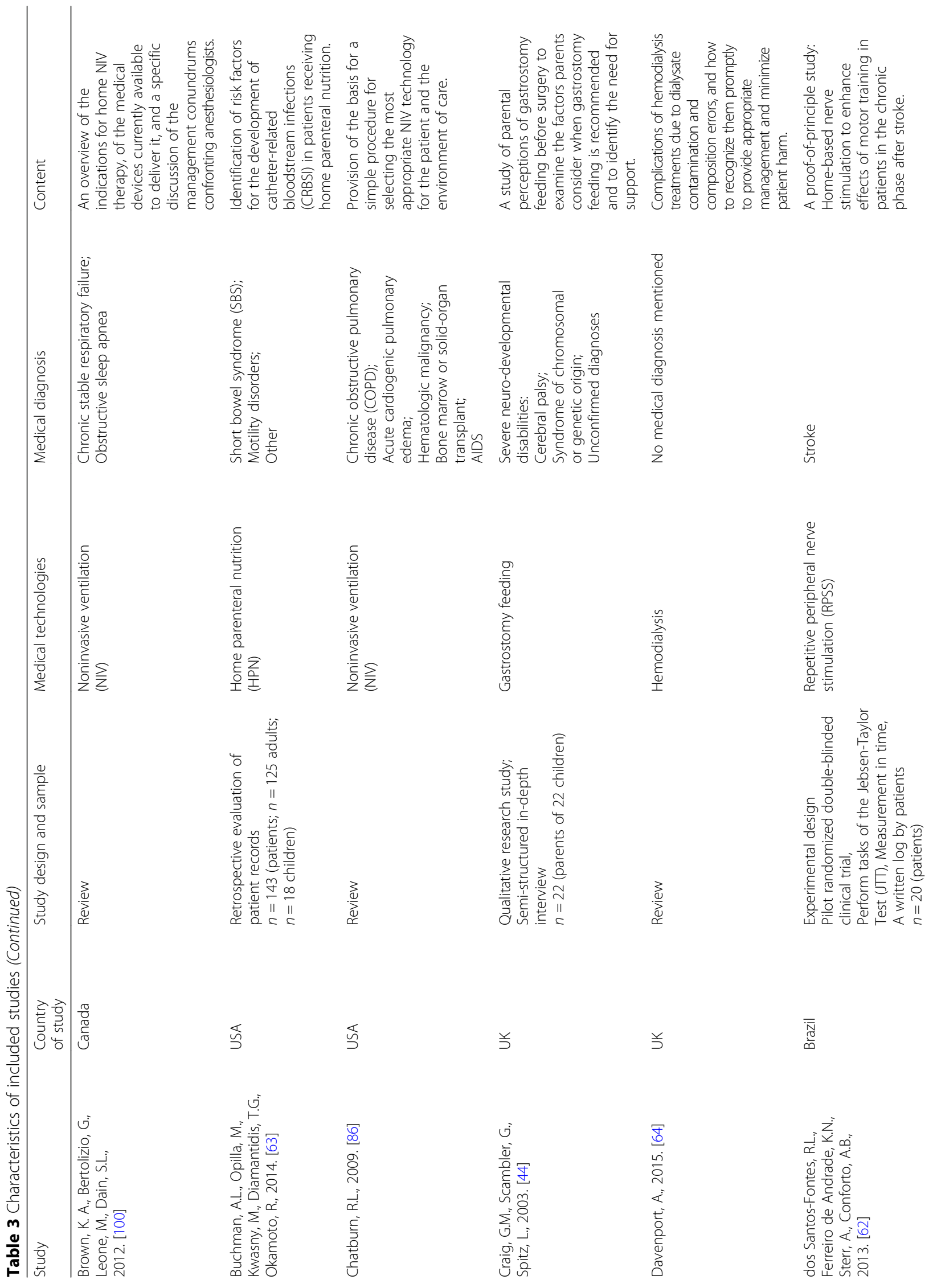




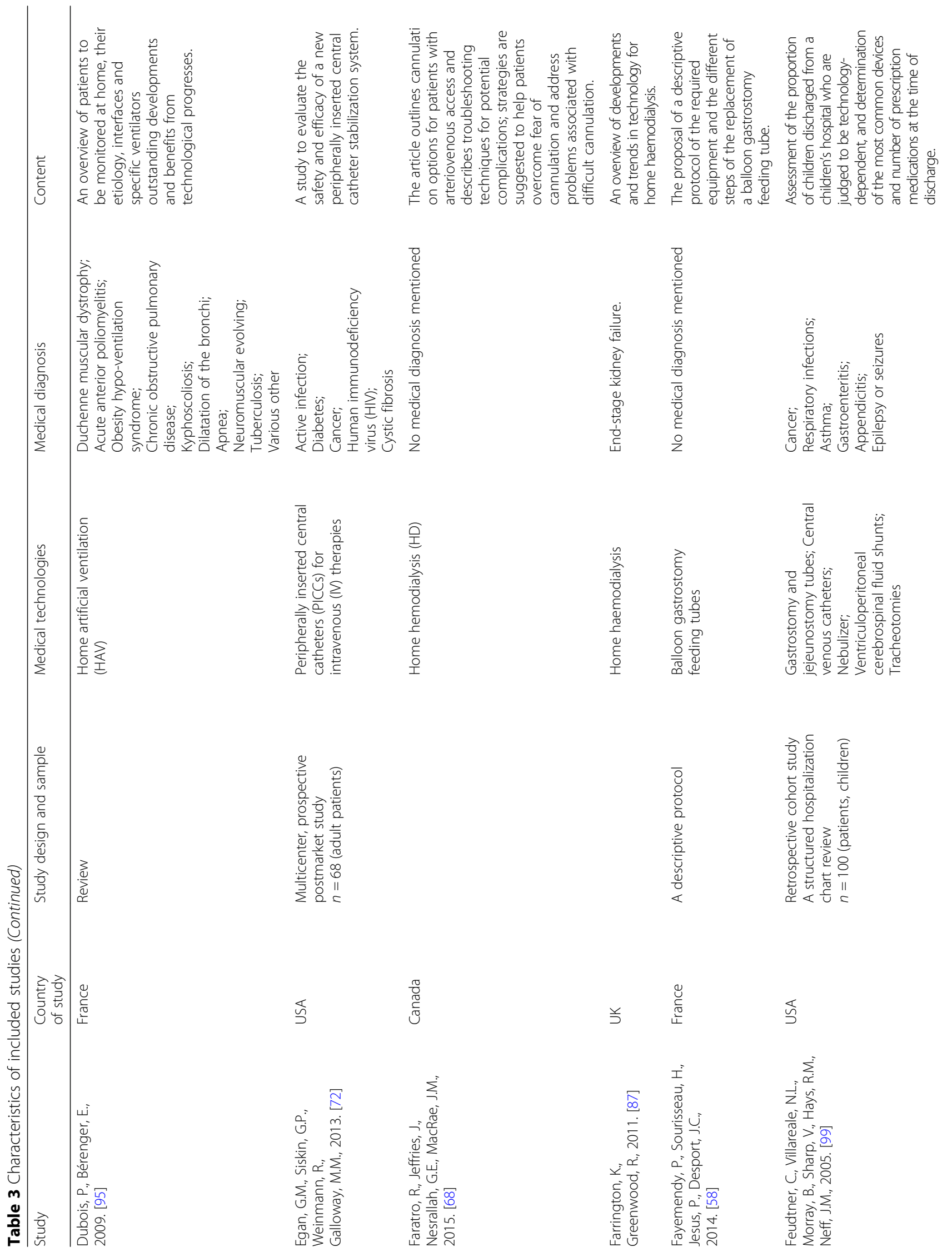




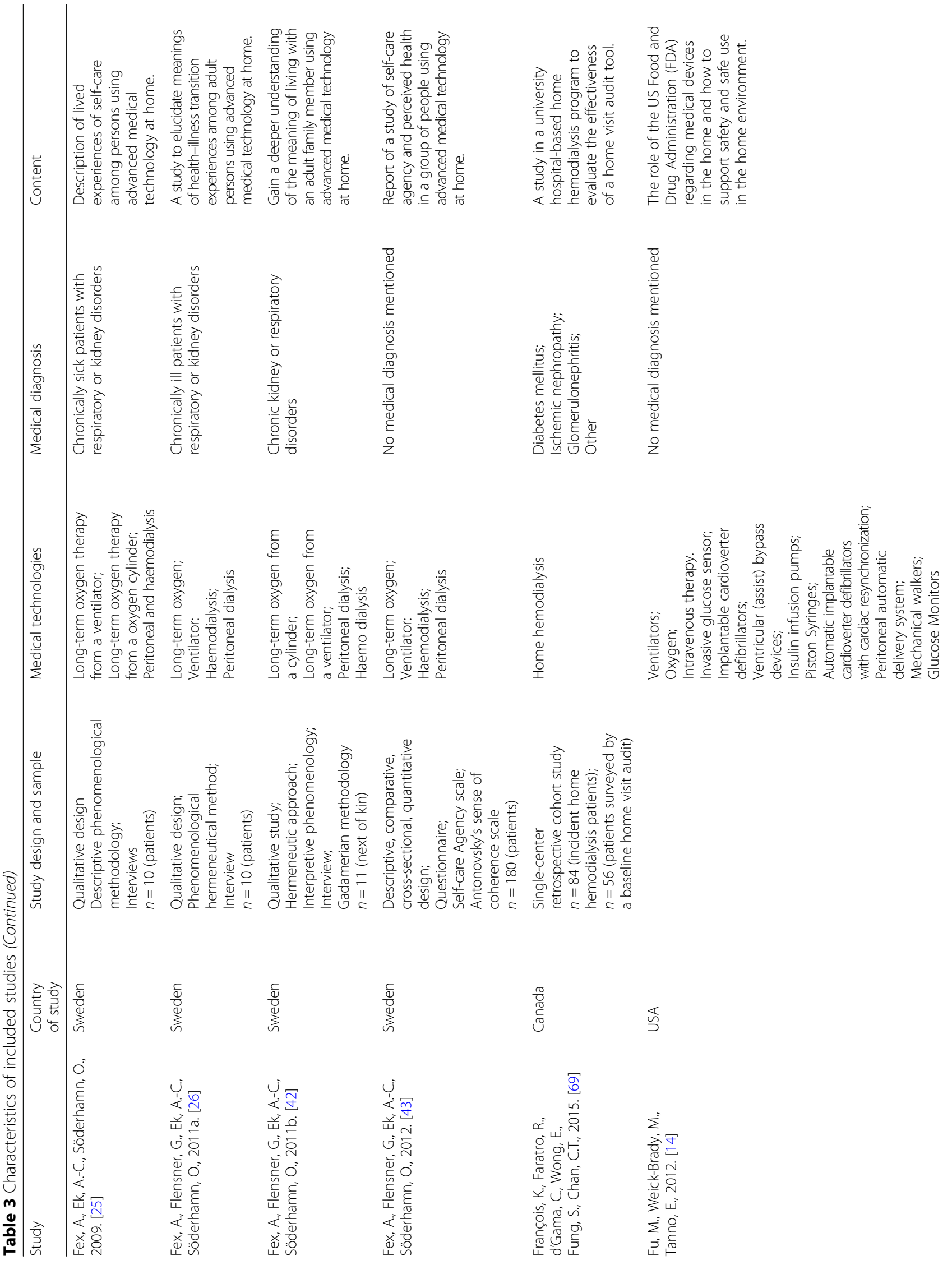




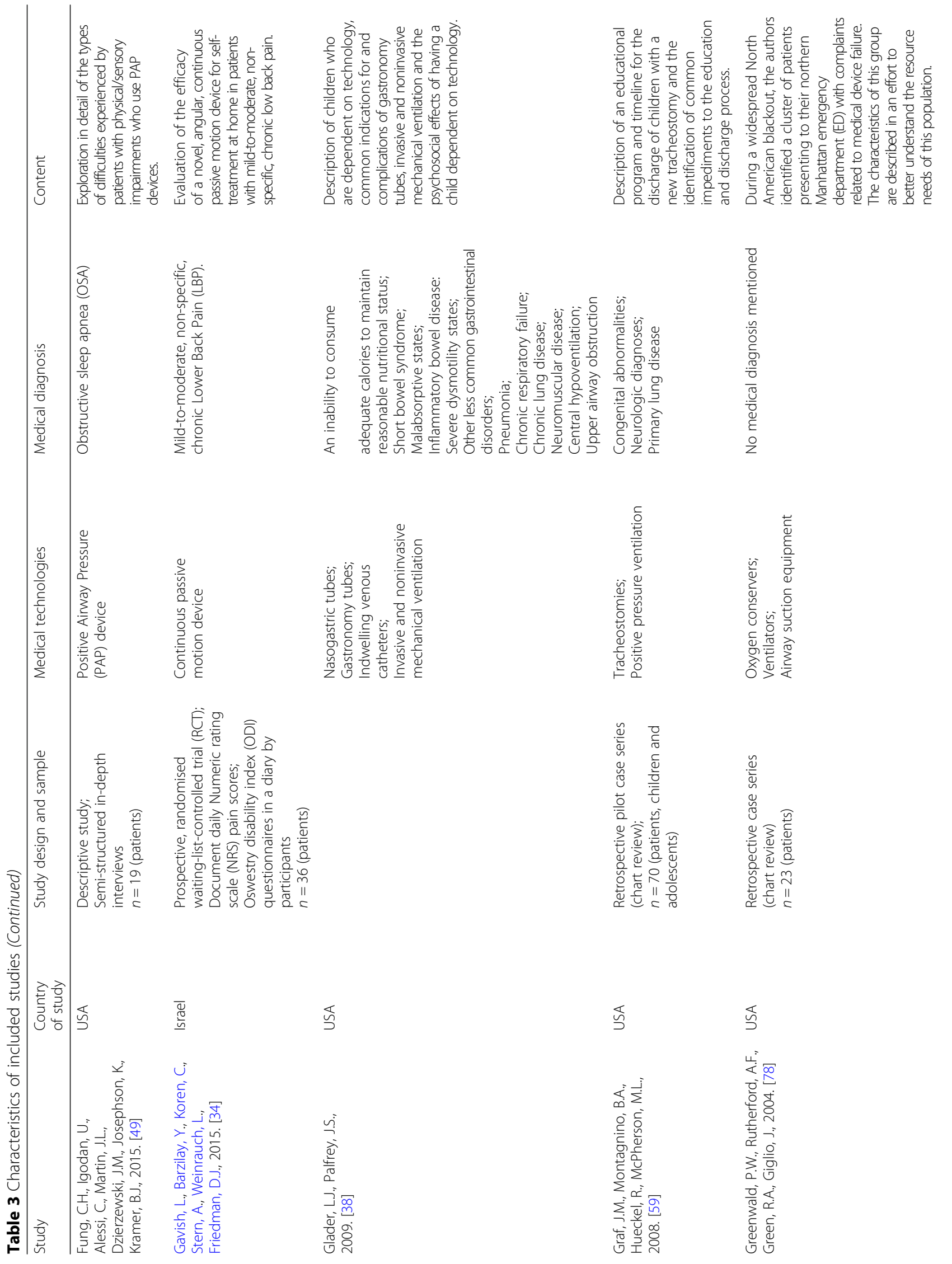




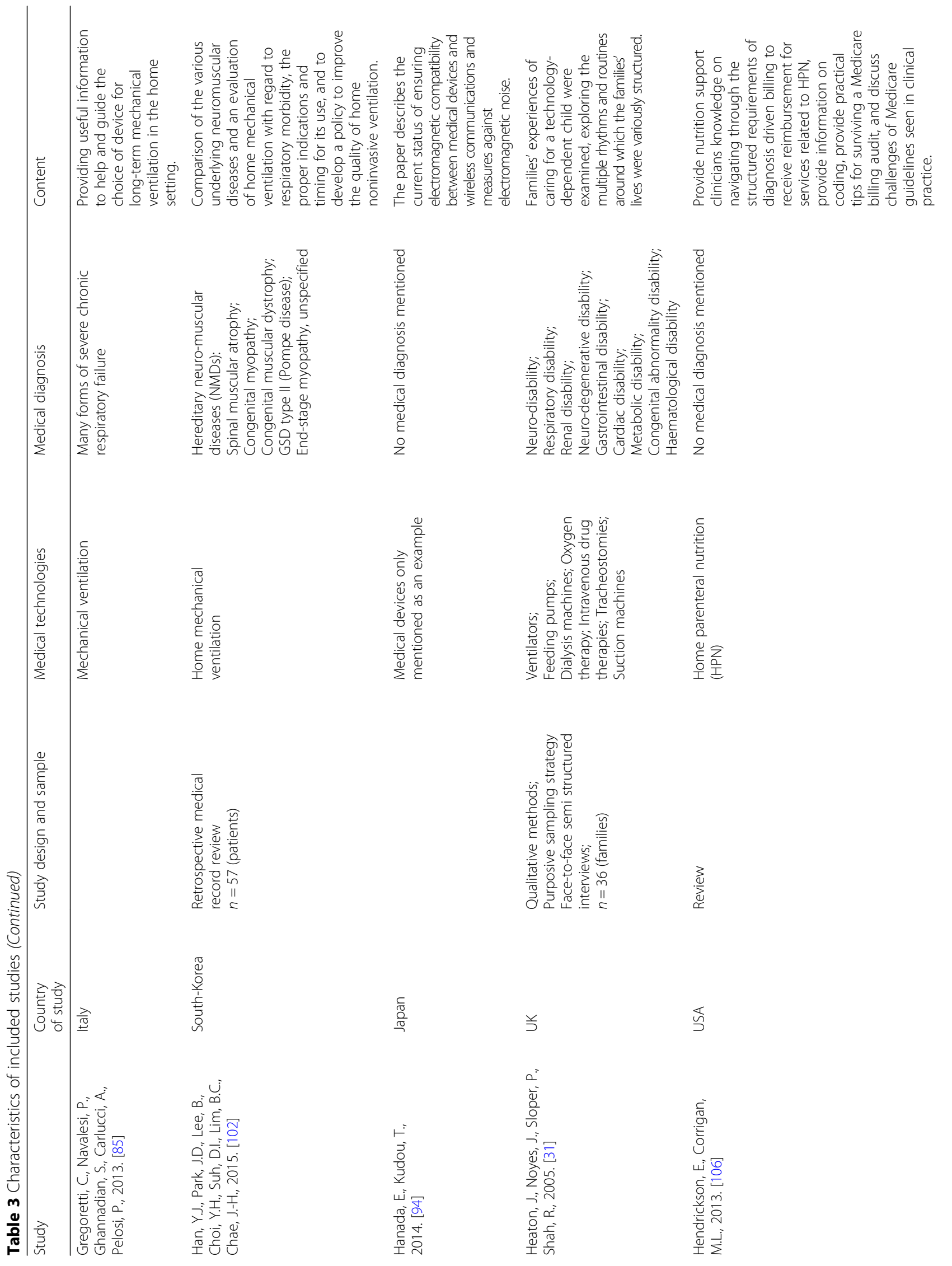




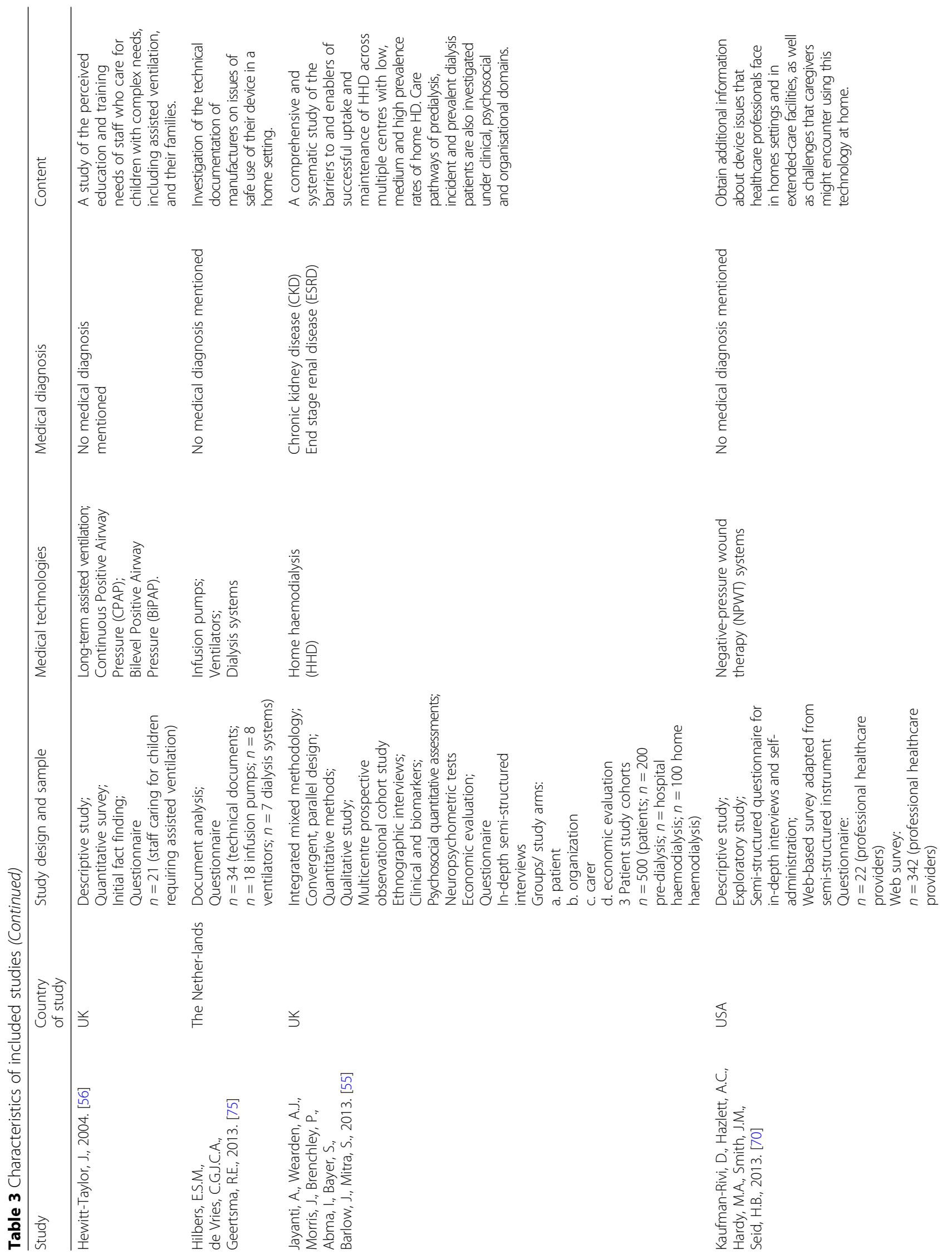




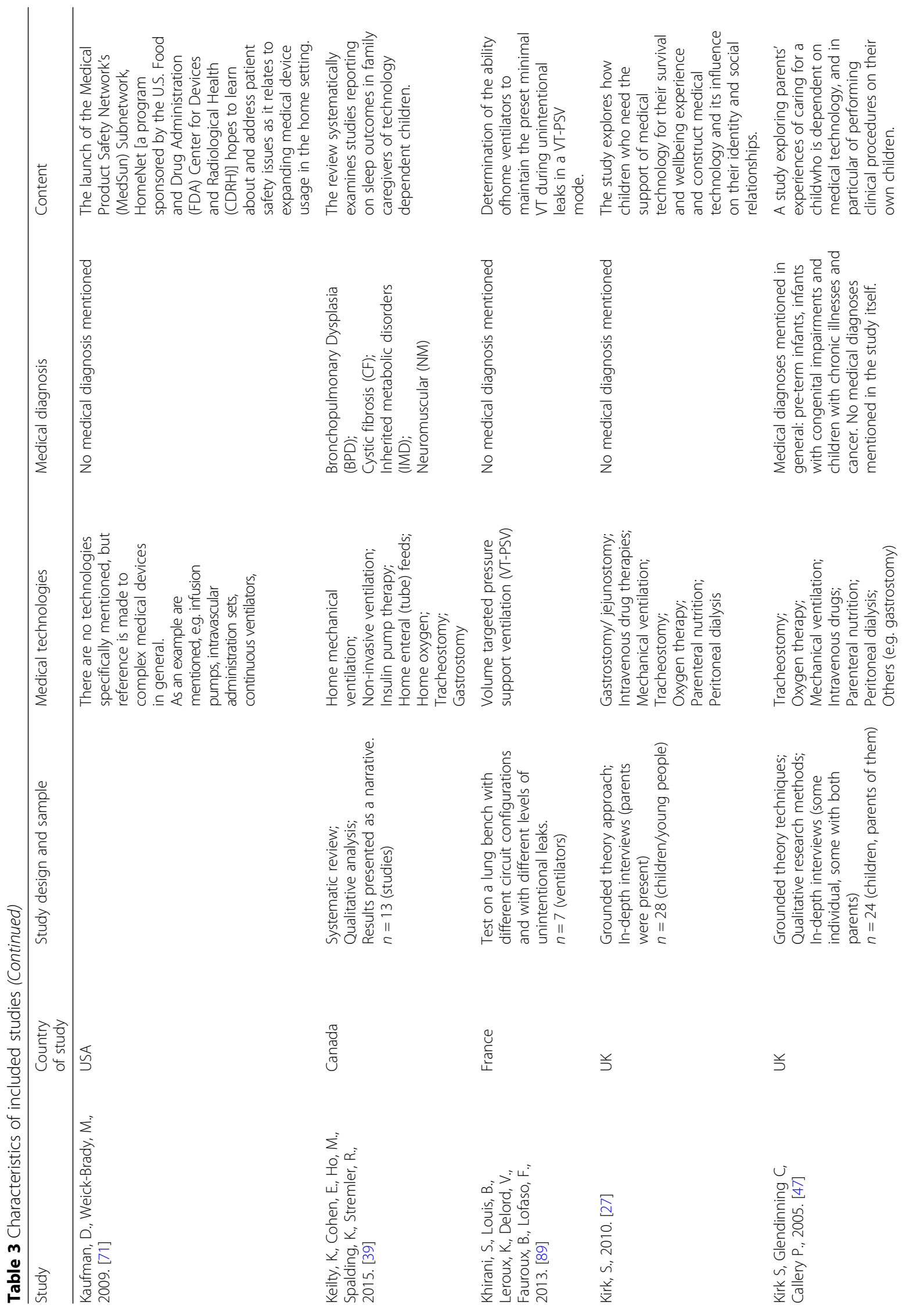




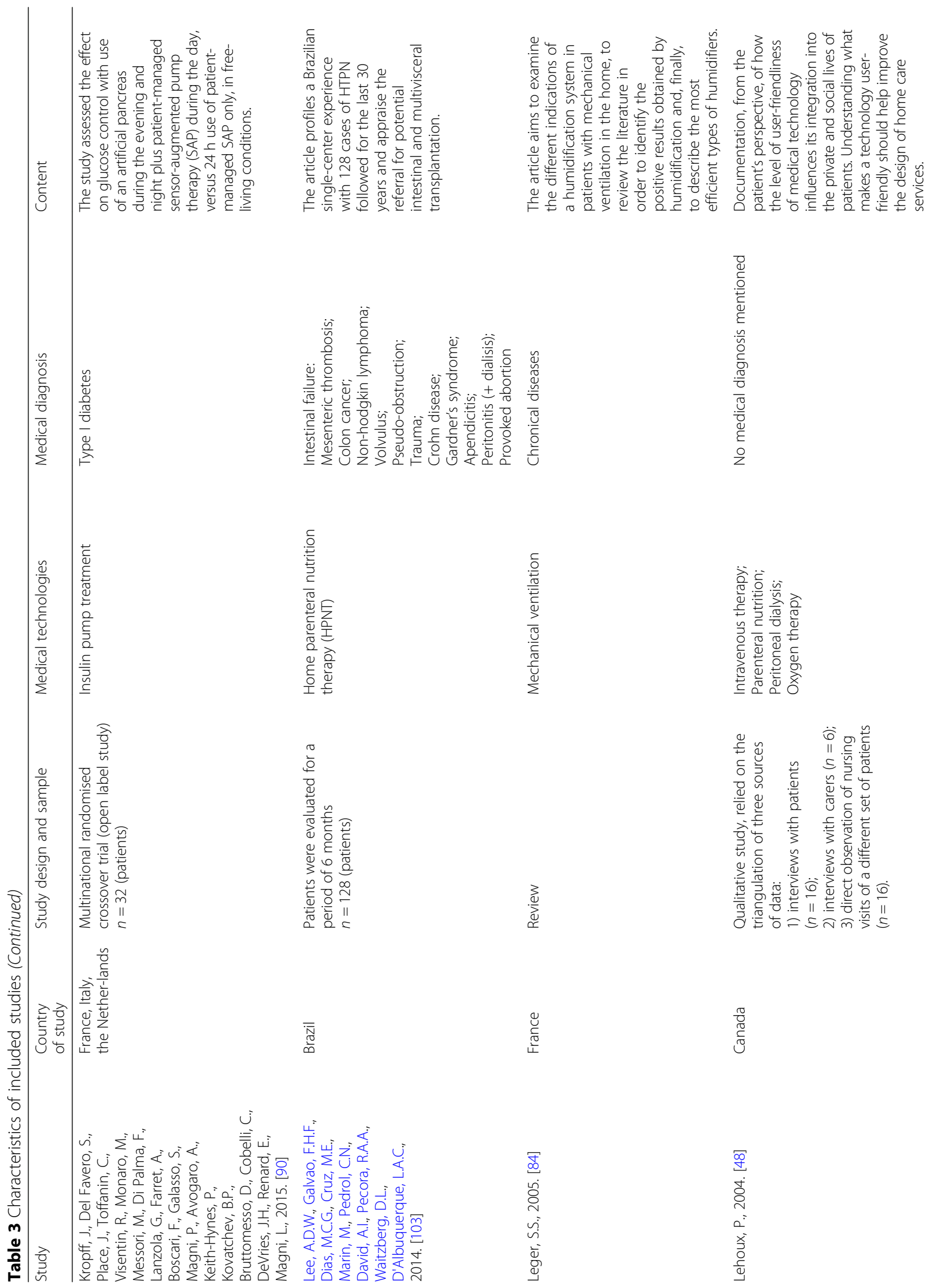




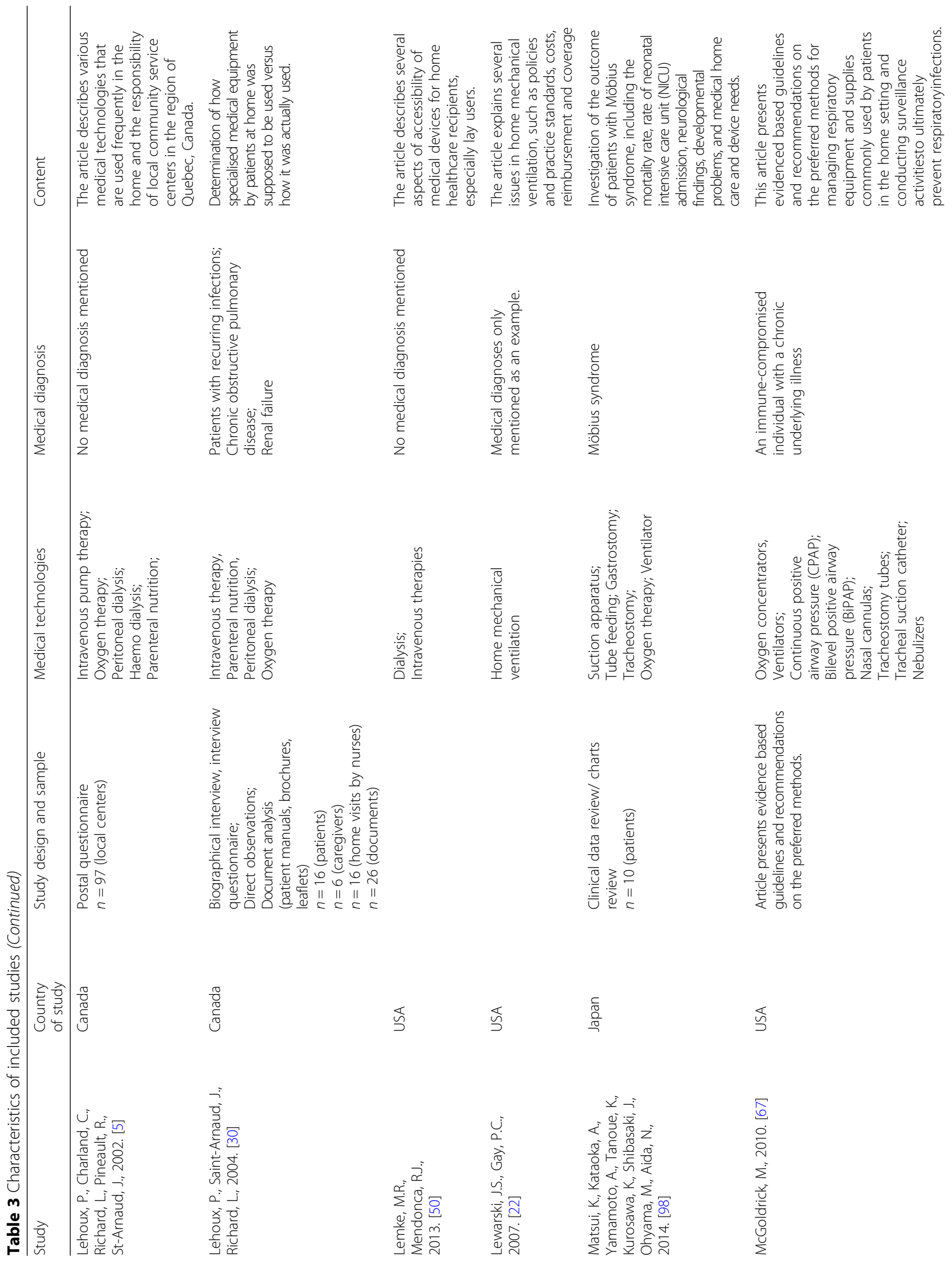




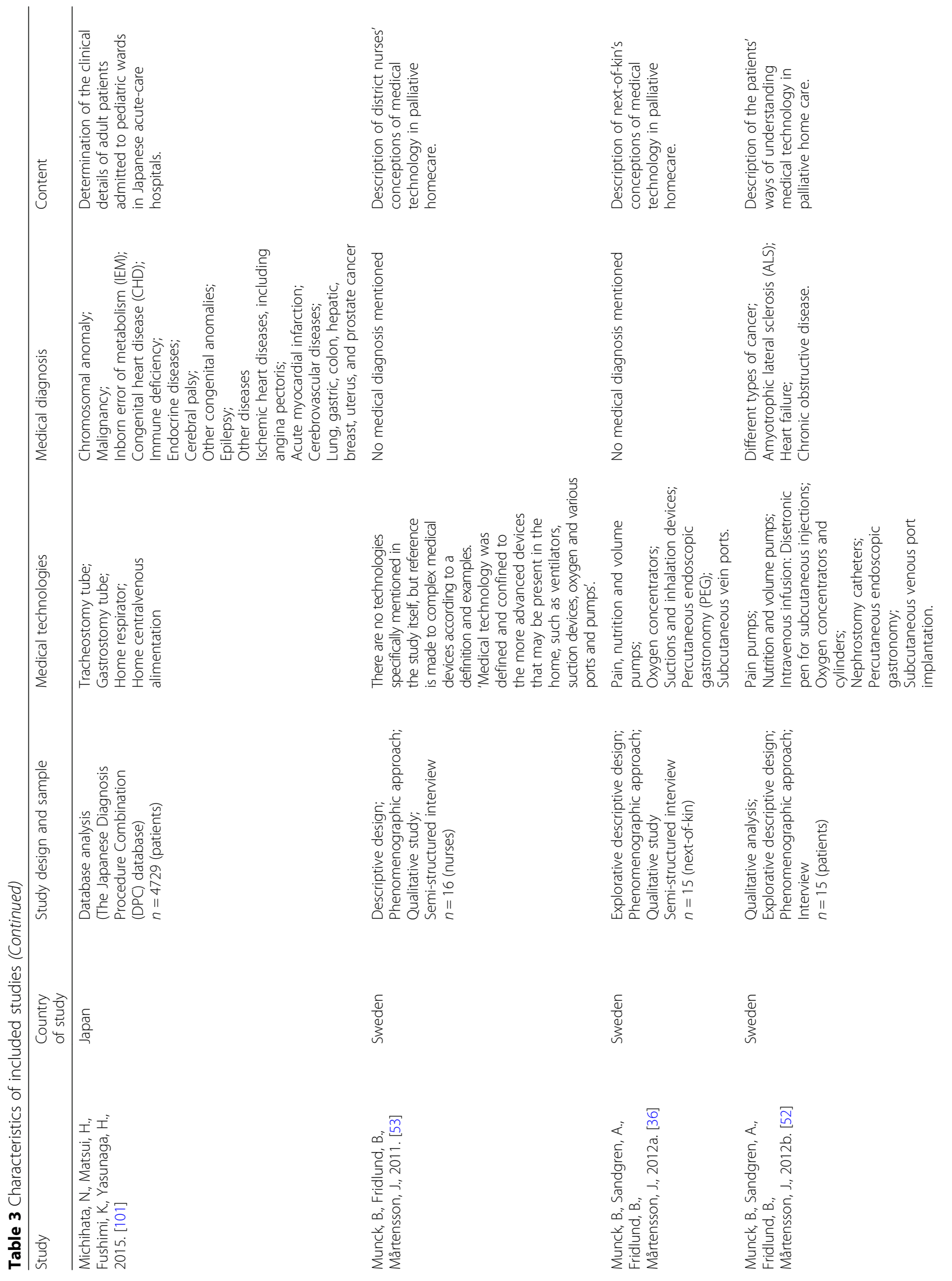




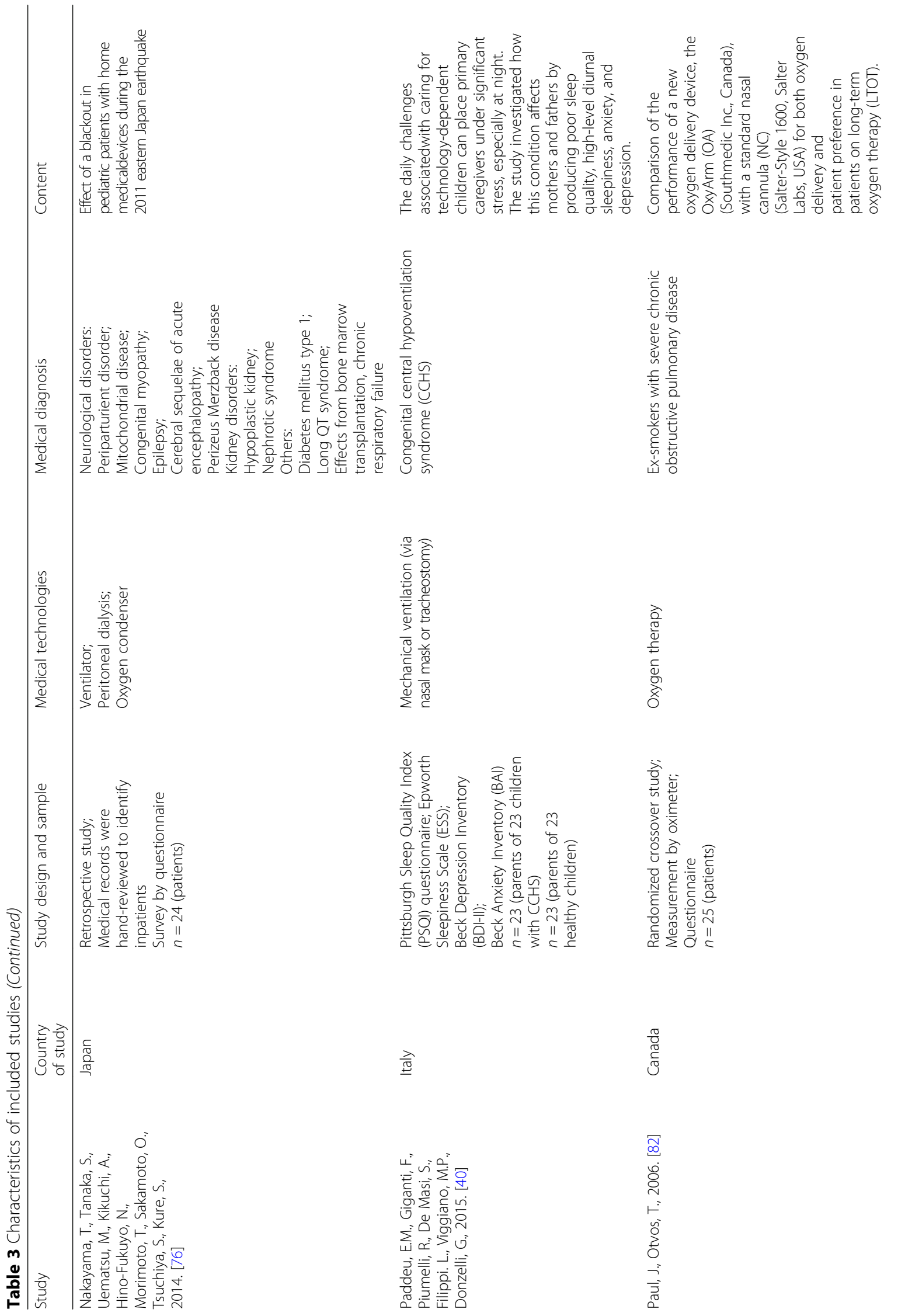




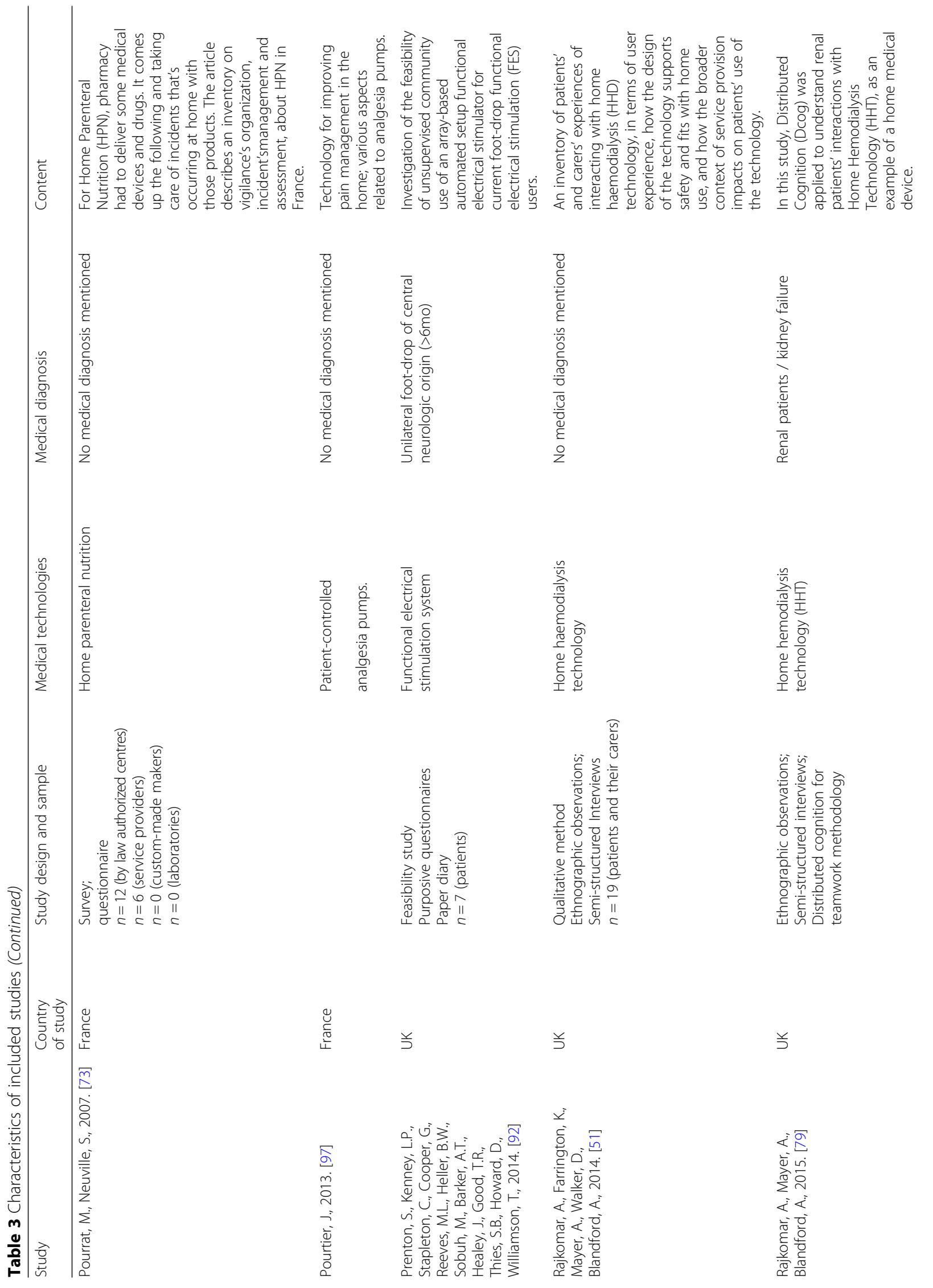




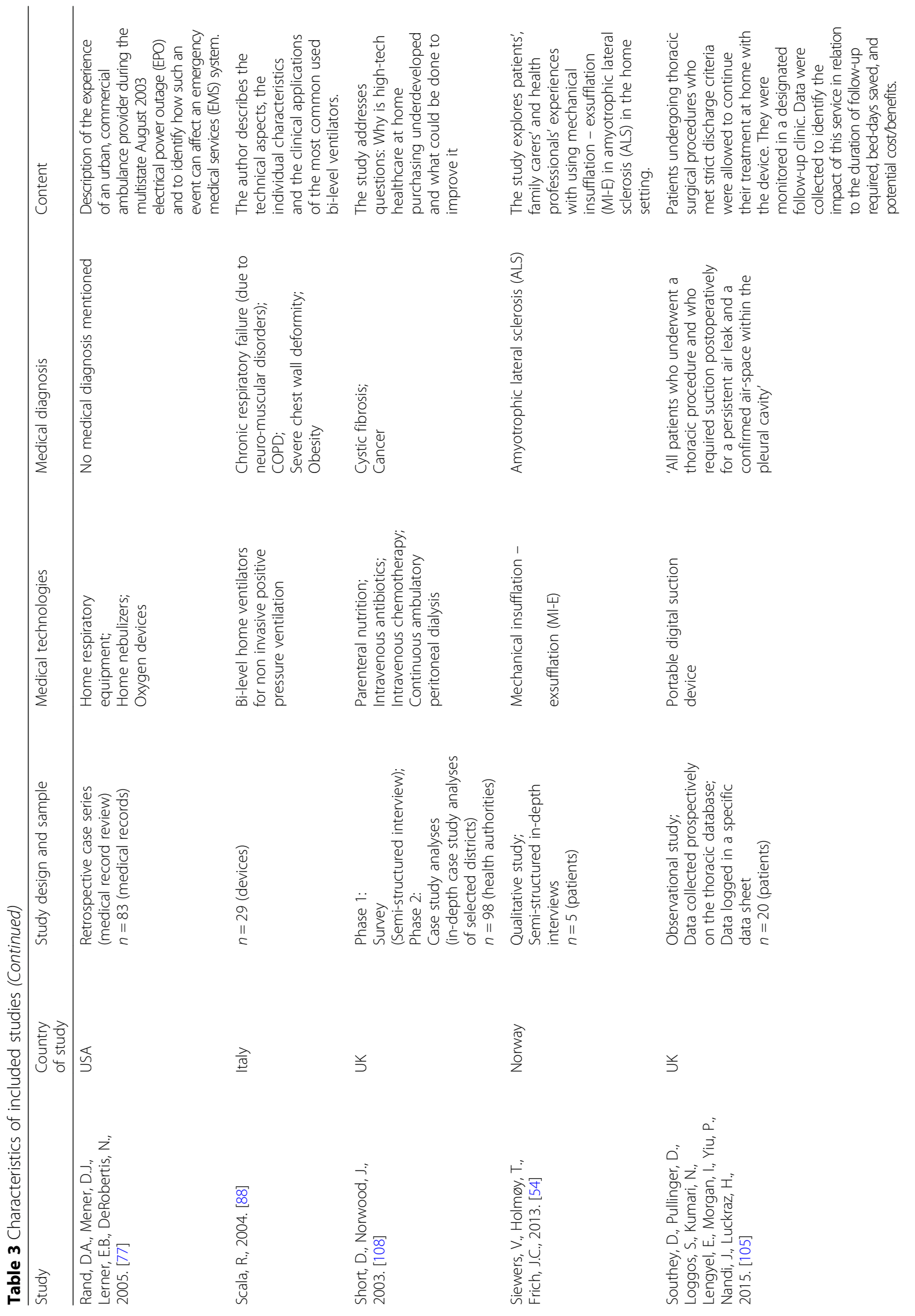




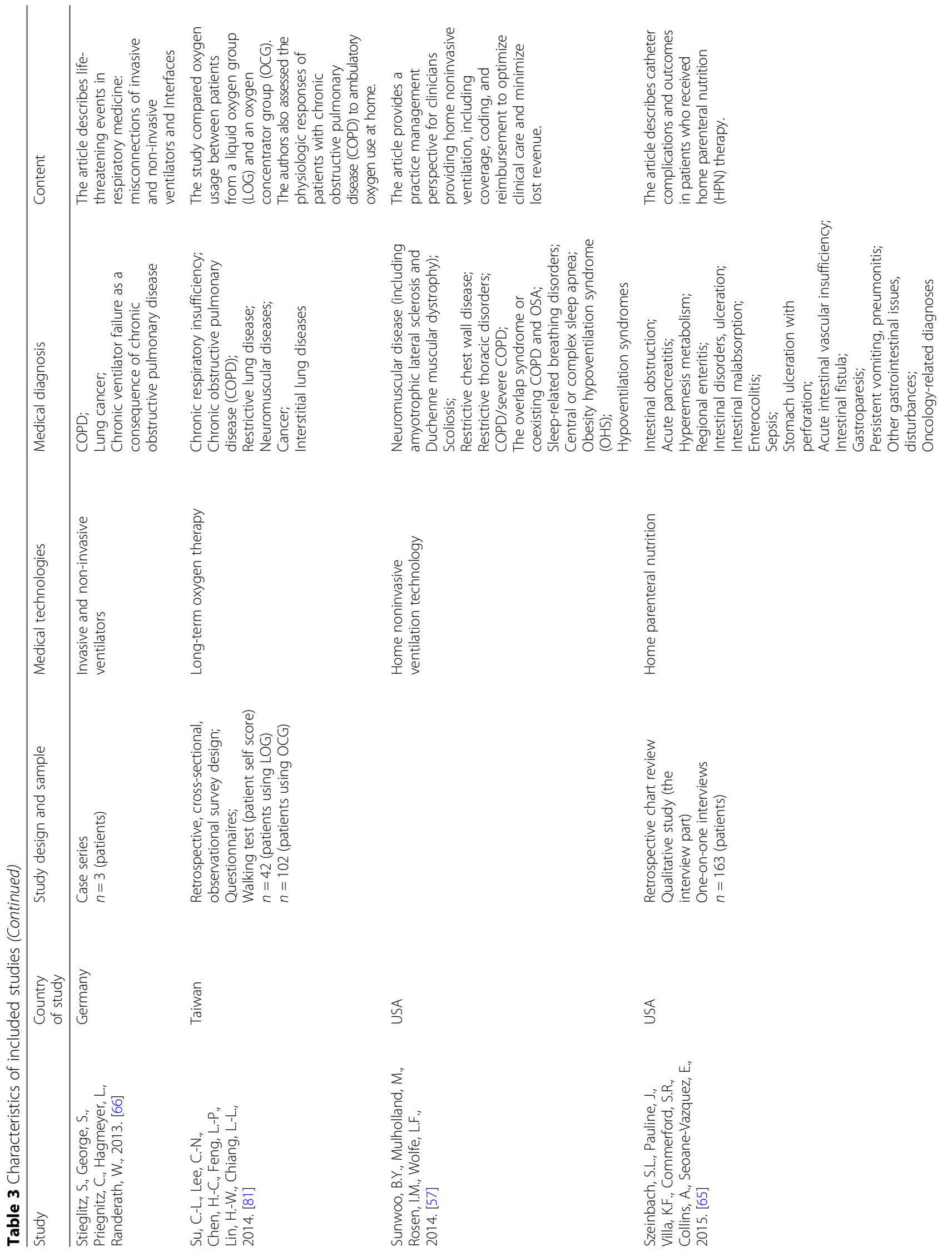




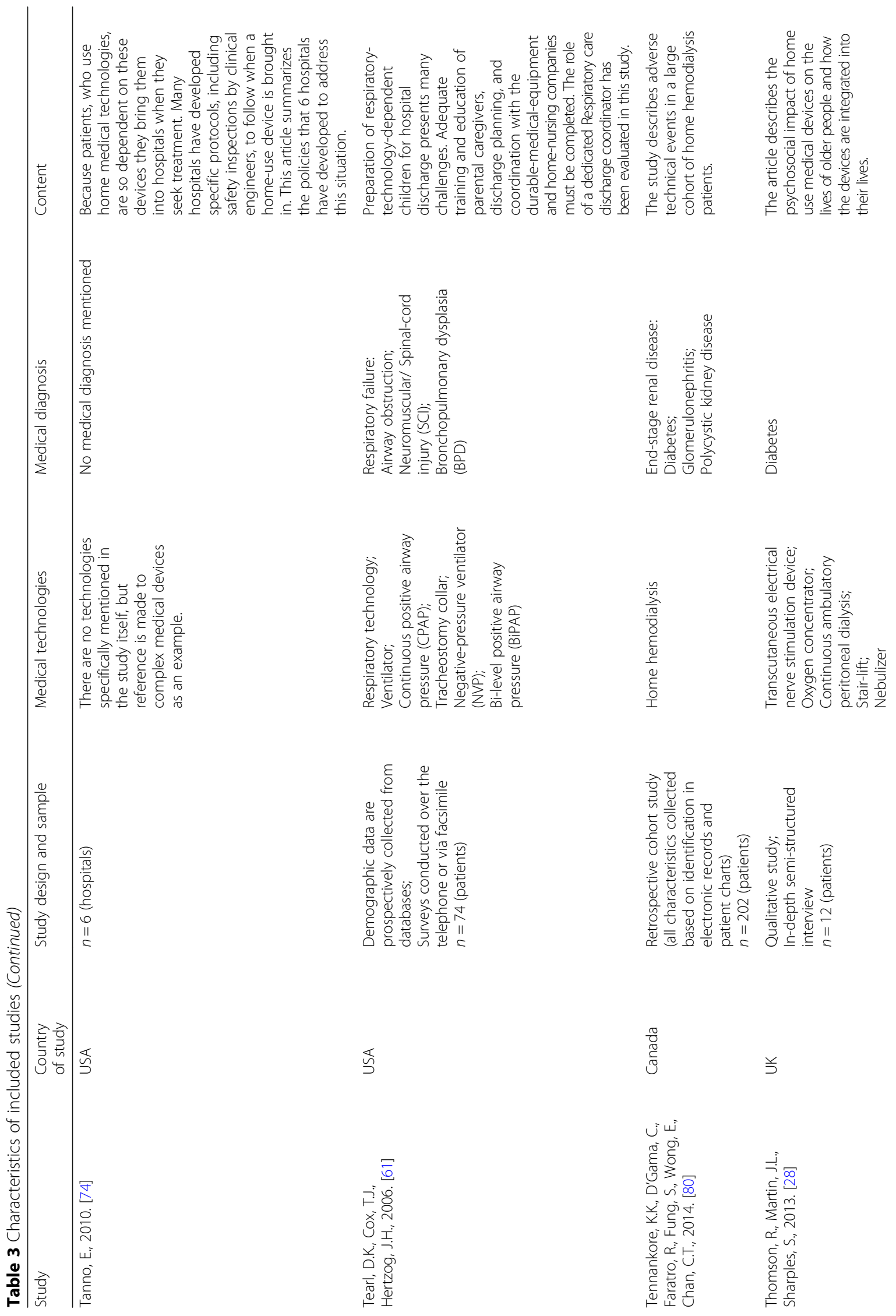




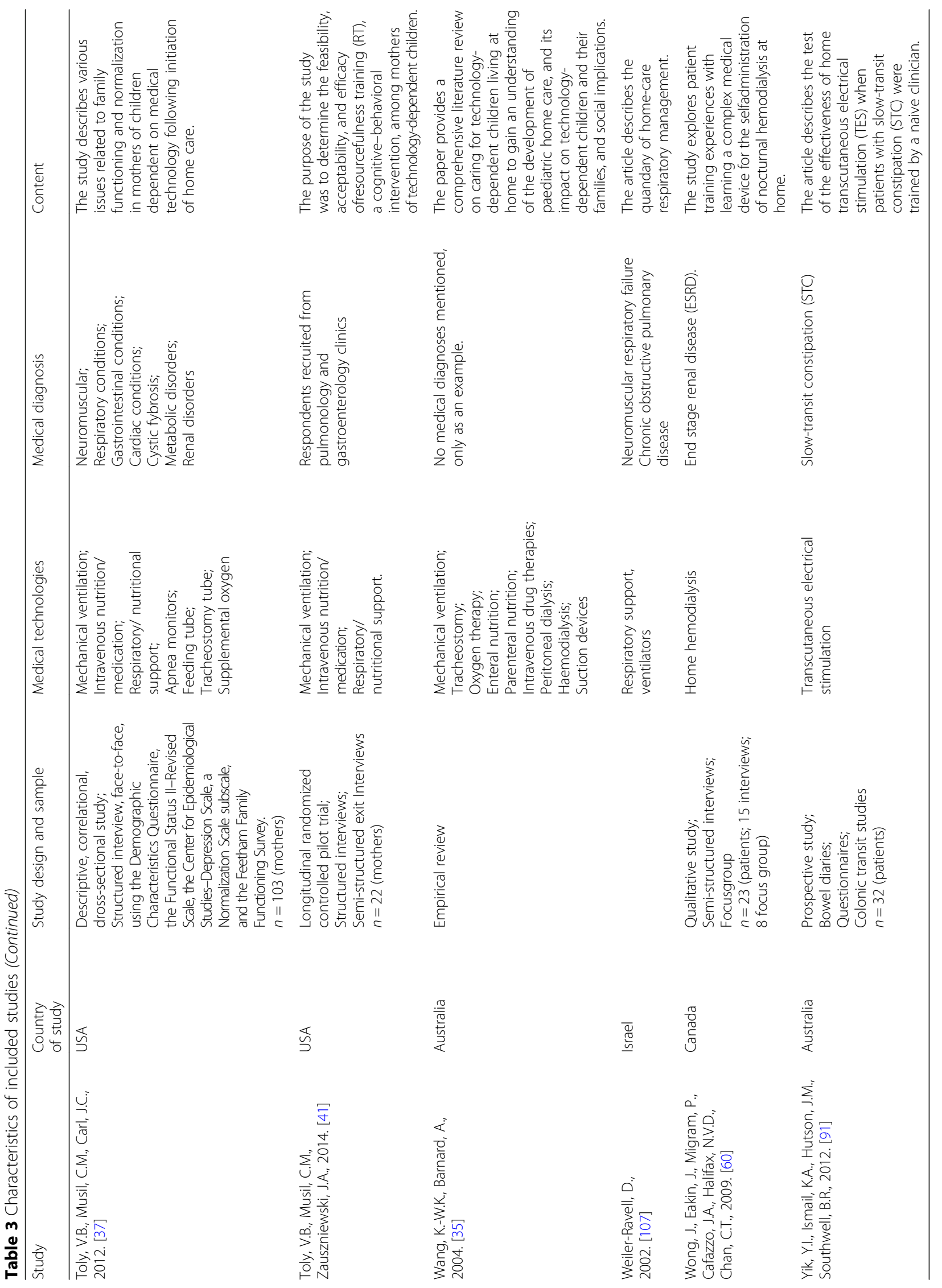




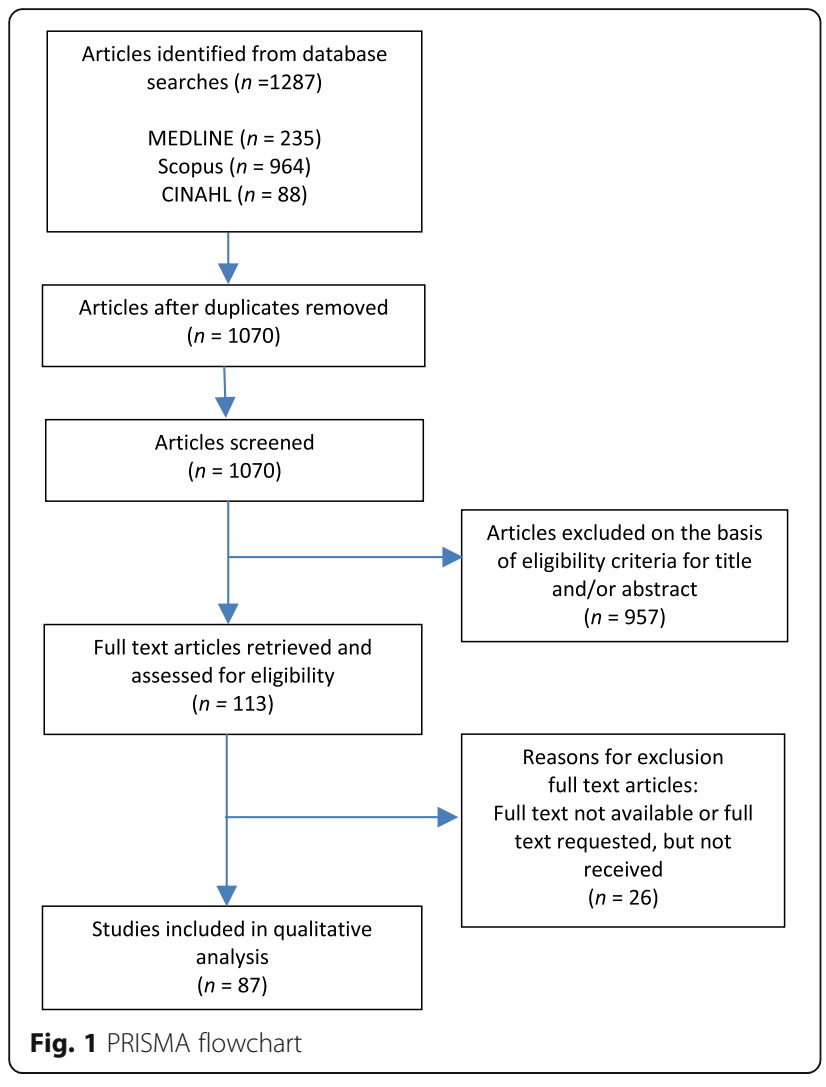

From an analysis of the articles, additional categories of content emerged:

4. Design and technological development

5. Application with regard to certain diseases or disorders, indication for and extent of use

6. Policy and management

\section{Types of medical technologies used, frequency of use} and trends

In four of the 87 articles (5\%) there were no specific medical technologies mentioned as a subject of study (see Table 4). Almost half of the studies (45\%) considered medical technologies for respiratory support and $39 \%$ devices for dialysis, either haemo- $(n=18)$, peritoneal- $(n=15)$ or dialysis not specified $(n=1)$. Of the studies, $29 \%$ reported on devices for oxygen therapy. In addition, there has been relatively more research conducted on equipment for 'infusion therapy' ( $n=19$; $22 \%)$, parenteral nutrition and enteral nutrition with a score of $20 \%$ each $(n=17)$. Relatively little research has been carried out on suction devices (8\%), external electrostimulation $(5 \%)$, nebulizer $(5 \%)$, insulin pump therapy $(3 \%)$, sleep apnea treatment $(2 \%)$, patient lifting hoists (2\%), vacuum assisted wound closure (1\%) and continuous passive motion (1\%). None of de studies considered medical technologies with regard to decubitus treatment, skeletal traction or UV (ultraviolet) therapy.

Table 4 shows that on the years 2000 and 2001 no relevant articles on the subject were found. Over the period 2000-2005, 17 articles were published, the same number over 2006-2010, and there has been a substantial increase in the number of publications to 54 over the years 2011-2015. In general, it can be concluded that more frequent investigated technologies show a fairly even distribution of publications over the years 2000-2015. Technologies, on which little research had been done, except for nebulizers, have been mainly investigated since 2010. An increase of published articles over the years 2000-2015 is apparent particularly for haemo dialysis and to a lesser extent, for devices for enteral- and parenteral nutrition. As mentioned before, several studies reported on the increase of the number of medical technologies used in home settings, but concrete data are not available. However, the number of studies and the visible trends may be indicative of the frequency of use.

In $63 \%$ of the cases $(n=55)$, a medical diagnosis (or diagnoses) was mentioned in the article. Where a diagnosis has been mentioned, in almost half of the studies $(n=26 ; 47 \%)$ it concerned diagnoses in the field of respiratory failure (see Fig. 2). This is not surprising, since 'respiratory support' is the medical technology most commonly found in the articles, similarly 'oxygen therapy' has also been considered relatively often. Diagnoses with regard to neurological disorders occurred in $42 \%$ of the studies $(n=23)$. Just over a quarter of the studies (27\%) considered diagnoses 'other', such as 'sepsis', 'chromosomal anomaly' or other not specified medical disorders, nearly a quarter (24\%) considered 'cancer' and 22\% kidney disorders $(n=12)$.

An analysis of the used research designs identified that $64 \%(n=56)$ of the studies used an observational (nonexperimental) design and only a small part of the studies ( $n=5 ; 6 \%$ ) used an experimental design, such as a Randomized Control Trial (RCT). Of the included studies 19 were reviews and 8 were essays. A quantitative design $(n=37)$ was used more frequently than a qualitative design $(n=25)$; and only one study applied 'mixed methods' (quantitative and qualitative). Just over onethird of the studies (35\%) used a descriptive design, and a similar number used a cross-sectional study (36\%). Case series were used in $12 \%$ of the articles and a cohort-study in 9\%. A phenomenological approach was applied in $16 \%$ of the records. Research instruments most frequently used were interviews (33\%) and survey/ questionnaires (21\%). In $10 \%$ of the cases other instruments were used, including different types of assessments or tests. 
Table 4 Trends in papers reporting on AMTs ( $n=87$, multiple answers possible), by year of publication (2000-2015)

\begin{tabular}{|c|c|c|c|c|c|c|c|c|c|c|c|c|c|c|c|c|c|}
\hline \multirow[b]{2}{*}{ Category of technology } & \multicolumn{17}{|c|}{ Year } \\
\hline & 2000 & 2001 & 2002 & 2003 & 2004 & 2005 & 2006 & 2007 & 2008 & 2009 & 2010 & 2011 & 2012 & 2013 & 2014 & 2015 & Total \\
\hline 1. Respiratory support & 0 & 0 & 1 & 1 & 5 & 4 & 1 & 1 & 1 & 4 & 2 & 2 & 4 & 5 & 4 & 4 & 39 \\
\hline 2. Sleep apnea treatment & 0 & 0 & 0 & 0 & 0 & 0 & 0 & 0 & 0 & 0 & 0 & 0 & 1 & 0 & 0 & 1 & 2 \\
\hline 3. Suction devices & 0 & 0 & 0 & 0 & 2 & 1 & 0 & 0 & 0 & 0 & 1 & 0 & 1 & 0 & 1 & 1 & 7 \\
\hline 4. Oxygen therapy & 0 & 0 & 1 & 0 & 4 & 3 & 1 & 0 & 0 & 1 & 2 & 2 & 5 & 1 & 4 & 1 & 25 \\
\hline 5. Dialysis & 0 & 0 & 0 & 0 & 0 & 0 & 0 & 0 & 0 & 0 & 0 & 0 & 0 & 1 & 0 & 0 & 1 \\
\hline a. Haemo & 0 & 0 & 1 & 0 & 1 & 1 & 0 & 0 & 0 & 2 & 0 & 3 & 2 & 2 & 2 & 4 & 18 \\
\hline b. Peritoneal & 0 & 0 & 1 & 1 & 3 & 1 & 0 & 0 & 0 & 1 & 1 & 2 & 2 & 2 & 1 & 0 & 15 \\
\hline 6. Vacuum ass.wound closure & 0 & 0 & 0 & 0 & 0 & 0 & 0 & 0 & 0 & 0 & 0 & 0 & 0 & 1 & 0 & 0 & 1 \\
\hline 7. Decubitus treatment & 0 & 0 & 0 & 0 & 0 & 0 & 0 & 0 & 0 & 0 & 0 & 0 & 0 & 0 & 0 & 0 & 0 \\
\hline 8. External electrostimulation & 0 & 0 & 0 & 0 & 0 & 0 & 0 & 0 & 0 & 0 & 0 & 0 & 1 & 2 & 1 & 0 & 4 \\
\hline 9. Continuous passive motion & 0 & 0 & 0 & 0 & 0 & 0 & 0 & 0 & 0 & 0 & 0 & 0 & 0 & 0 & 0 & 1 & 1 \\
\hline 10. Skeletal traction & 0 & 0 & 0 & 0 & 0 & 0 & 0 & 0 & 0 & 0 & 0 & 0 & 0 & 0 & 0 & 0 & 0 \\
\hline 11. Patient lifting hoists & 0 & 0 & 0 & 0 & 0 & 0 & 0 & 0 & 0 & 0 & 1 & 0 & 0 & 1 & 0 & 0 & 2 \\
\hline 12. Infusion therapy & 0 & 0 & 1 & 1 & 3 & 3 & 0 & 0 & 0 & 0 & 1 & 0 & 4 & 4 & 1 & 1 & 19 \\
\hline 13. Insulin pump therapy & 0 & 0 & 0 & 0 & 0 & 0 & 0 & 0 & 0 & 0 & 0 & 0 & 0 & 0 & 1 & 2 & 3 \\
\hline 14. Parenteral nutrition & 0 & 0 & 1 & 1 & 3 & 1 & 0 & 1 & 0 & 0 & 1 & 0 & 2 & 1 & 3 & 3 & 17 \\
\hline 15. Enteral nutrition & 0 & 0 & 0 & 1 & 1 & 3 & 0 & 0 & 0 & 1 & 1 & 0 & 4 & 0 & 3 & 3 & 17 \\
\hline 16. UV therapy & 0 & 0 & 0 & 0 & 0 & 0 & 0 & 0 & 0 & 0 & 0 & 0 & 0 & 0 & 0 & 0 & 0 \\
\hline 17. Nebulizer & 0 & 0 & 0 & 0 & 0 & 2 & 0 & 0 & 0 & 0 & 1 & 0 & 0 & 1 & 0 & 0 & 4 \\
\hline $\begin{array}{l}\text { No medical technology } \\
\text { mentioned }\end{array}$ & 0 & 0 & 0 & 0 & 0 & 0 & 0 & 0 & 0 & 1 & 1 & 1 & 0 & 0 & 1 & 0 & 4 \\
\hline Total & 0 & 0 & 2 & 3 & 7 & 5 & 2 & 2 & 1 & 7 & 4 & 5 & 8 & 13 & 13 & 15 & 87 \\
\hline
\end{tabular}

No shading $n=0$, up till the darkest shading $n=5$

With regard to the categories of content, most research has been carried out on 'user experiences' (see Fig. 3): just over one-third of the articles $(n=31 ; 36 \%)$ focused on this topic. Of these articles almost all studies focused on experiences of patients or informal caregivers $(n=29)$ and only a small number $(n=2)$ considered the user experiences of nurses or other professionals (see Table 5). More than half of the studies $(n=19)$ used a qualitative research design; of these 13 used a phenomenological approach. The goal of these studies was to elicit the essence of human phenomena as experienced by the users. Seven studies used a quantitative design and one an integrated mixed method. Three of the studies applied a grounded theory approach and two

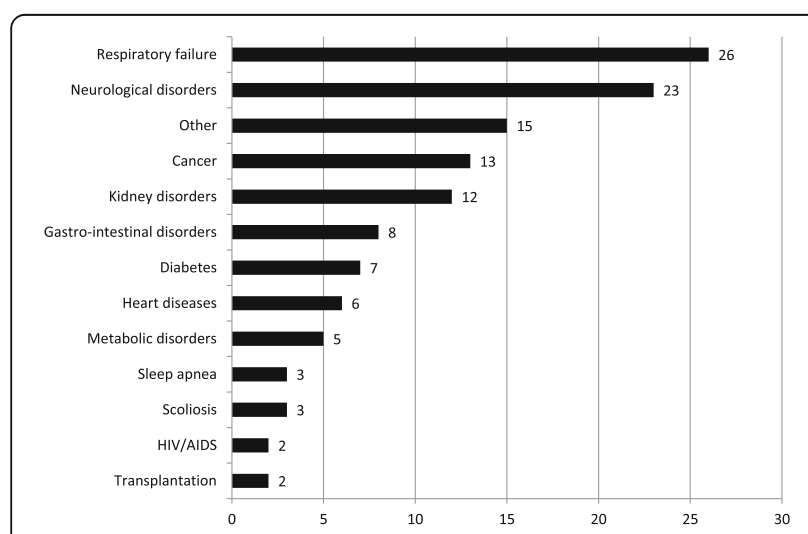

Fig. 2 Number of medical diagnoses mentioned in articles on AMTs ( $n=87$, multiple answers possible) an experimental design (randomized controlled trial). The research instruments in this content category to collect data were interviews, either semi-structured or in-depth, and a survey. About two-thirds of the articles regarding 'user experiences' were published in the period 2011-2015, with an accent on the psychosocial impact of patients or informal caregivers.

Relatively little research was found on 'training, instruction, education' $(n=7)$, for the use of AMTs in home settings. It was remarkable that all the studies identified as focusing on this topic, concentrated on one category of AMT. Respiratory support was the subject of study in four instances and in the other three, the focus was on technologies for enteral nutrition, haemo dialysis and external electro-stimulation. Four of the seven

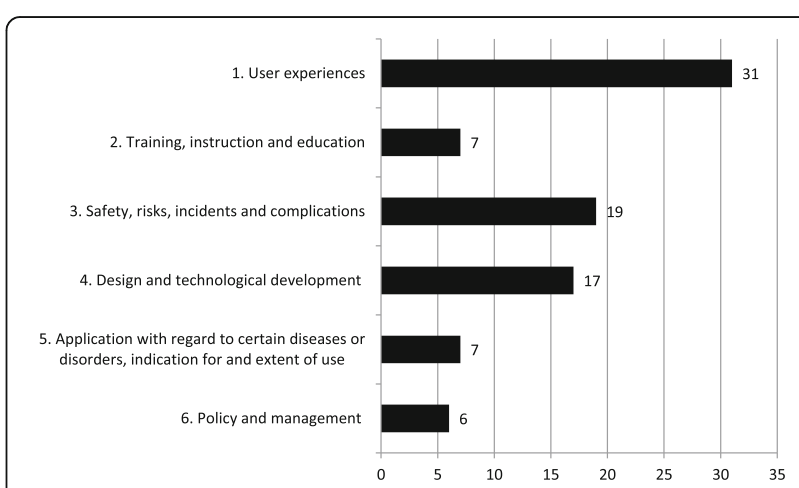

Fig. 3 Number of articles on AMTs with main content categories $(n=87)$ 
Table 5 Subcateogories of content in selected articles on AMTs ( $n=87$ ) by year of publication (2000-2015)

\begin{tabular}{|c|c|c|c|c|c|c|c|c|c|c|c|c|c|c|c|c|c|}
\hline \multirow[b]{2}{*}{ Subcategory of content } & \multicolumn{17}{|c|}{ Year } \\
\hline & 2000 & 2001 & 2002 & 2003 & 2004 & 2005 & 2006 & 2007 & 2008 & 2009 & 2010 & 2011 & 2012 & 2013 & 2014 & 2015 & Total \\
\hline $\begin{array}{l}\text { 1a. User experiences of nurses or other } \\
\text { professionals: usability, barriers, accessibility }\end{array}$ & 0 & 0 & 0 & 0 & 0 & 0 & 0 & 0 & 0 & 0 & 0 & 1 & 0 & 1 & 0 & 0 & 2 \\
\hline $\begin{array}{l}\text { 1b. User experiences of patients or informal } \\
\text { caregivers: usability, barriers, accessibility }\end{array}$ & 0 & 0 & 0 & 1 & 1 & 0 & 0 & 0 & 0 & 0 & 0 & 0 & 1 & 2 & 1 & 1 & 7 \\
\hline $\begin{array}{l}\text { 1c. User experiences of patients or informal } \\
\text { caregivers: psychosocial impact }\end{array}$ & 0 & 0 & 0 & 0 & 3 & 2 & 0 & 0 & 0 & 3 & 1 & 3 & 3 & 1 & 2 & 4 & 22 \\
\hline $\begin{array}{l}\text { 2a. Training, instruction and education of } \\
\text { nurses or other professionals }\end{array}$ & 0 & 0 & 0 & 0 & 1 & 0 & 0 & 0 & 0 & 0 & 0 & 0 & 0 & 0 & 2 & 0 & 3 \\
\hline $\begin{array}{l}\text { 2b. Training, instruction and education of } \\
\text { patients or informal caregivers }\end{array}$ & 0 & 0 & 0 & 0 & 0 & 0 & 1 & 0 & 1 & 1 & 0 & 0 & 0 & 1 & 0 & 0 & 4 \\
\hline $\begin{array}{l}\text { 3a. Safety general: safe use, factors affecting } \\
\text { safety, complications, prevention }\end{array}$ & 0 & 0 & 0 & 0 & 0 & 0 & 0 & 0 & 0 & 0 & 1 & 0 & 0 & 2 & 1 & 2 & 6 \\
\hline $\begin{array}{l}\text { 3b. Safety general: safe transfer of } \\
\text { equipment from hospital to the home and } \\
\text { vice versa }\end{array}$ & 0 & 0 & 0 & 0 & 0 & 0 & 0 & 0 & 0 & 0 & 1 & 0 & 1 & 0 & 0 & 0 & 2 \\
\hline $\begin{array}{l}\text { 3c. Safety general: monitoring, evaluating, } \\
\text { assessing safety }\end{array}$ & 0 & 0 & 0 & 0 & 0 & 0 & 0 & 1 & 0 & 1 & 0 & 0 & 0 & 1 & 0 & 2 & 5 \\
\hline 3e. Safety environmental factors & 0 & 0 & 0 & 0 & 1 & 1 & 0 & 0 & 0 & 0 & 0 & 0 & 0 & 0 & 1 & 0 & 3 \\
\hline 3f. Safety human factors: general & 0 & 0 & 0 & 0 & 0 & 0 & 0 & 0 & 0 & 0 & 0 & 0 & 0 & 0 & 0 & 1 & 1 \\
\hline $\begin{array}{l}\text { 3g. Safety human factors: user errors by } \\
\text { nurses or other professionals }\end{array}$ & 0 & 0 & 0 & 0 & 0 & 0 & 0 & 0 & 0 & 0 & 0 & 0 & 0 & 0 & 0 & 0 & 0 \\
\hline $\begin{array}{l}\text { 3h. Safety human factors: user errors by } \\
\text { patients or informal caregivers }\end{array}$ & 0 & 0 & 0 & 0 & 0 & 0 & 0 & 0 & 0 & 0 & 0 & 0 & 0 & 0 & 1 & 0 & 1 \\
\hline $\begin{array}{l}\text { 4a. Design and technological development } \\
\text { equipment: comparison between, advantages } \\
\text { and disadvantages of different types }\end{array}$ & 0 & 0 & 0 & 0 & 1 & 1 & 1 & 0 & 0 & 1 & 0 & 1 & 0 & 2 & 1 & 2 & 10 \\
\hline $\begin{array}{l}\text { 4b. Design and technological development } \\
\text { equipment: development, effectivity }\end{array}$ & 0 & 0 & 0 & 0 & 0 & 0 & 0 & 0 & 0 & 1 & 1 & 0 & 2 & 1 & 2 & 0 & 7 \\
\hline $\begin{array}{l}\text { 5. Application of technologies with regard to } \\
\text { certain diseases or disorders, indication for } \\
\text { and extent of use }\end{array}$ & 0 & 0 & 0 & 1 & 0 & 1 & 0 & 0 & 0 & 0 & 0 & 0 & 1 & 0 & 2 & 2 & 7 \\
\hline 6. Policy and management & 0 & 0 & 2 & 1 & 0 & 0 & 0 & 1 & 0 & 0 & 0 & 0 & 0 & 1 & 0 & 1 & 6 \\
\hline Total & 0 & 0 & 2 & 3 & 7 & 5 & 2 & 2 & 1 & 7 & 4 & 5 & 8 & 13 & 13 & 15 & 87 \\
\hline
\end{tabular}

No shading $n=0$, up till the darkest shading $n=4$

articles utilized quantitative methods, among which three of them used an observational non-experimental design and one was an experimental randomized double-blind clinical trial. Another study within the initial seven articles used a qualitative observational nonexperimental design, one was a review and another was in essay format.

In total, $22 \%$ of the articles discussed topics on safety, risks, incidents and complications $(n=19)$. In the majority of cases $(n=13)$ general aspects about the subject, for instance safe use, factors affecting safety, a safe transfer of the equipment and monitoring of assessing safety were considered. One article described technological factors with regard to safety, three articles reported on environmental factors and two explored human factors. Safety aspects were explored over a wide range of medical technologies. Five articles were reviews and one an essay. Quantitative methods were used in ten of the cases, particularly for monitoring, evaluating and assessing safety, technological and environmental factors. Only three studies used a qualitative design. Retrospective chart reviews or case series were used to collect data in some cases of unforeseen events. Table 5 shows about a doubling of published articles in the period 2011-2015 regarding this content category, compared to the previous period 2000-2010.
Approximately $20 \%$ of the selected articles considered the content category 'design and technological development of the medical device' $(n=17)$. The studies each focused on only one type of AMT and treated a relative wide range of eight different categories, such as 'respiratory support', 'oxygen therapy', 'haemo dialysis', 'infusion therapy', 'insulin pump therapy' and 'enteral nutrition', but also 'external electrostimulation' and 'patient lifting hoists'. Interestingly, in this group of articles, relatively often $(n=6)$ no medical diagnosis was mentioned. Around half of the studies $(n=8)$ referring to this topic were in review or essay format. All other studies used a quantitative research design and throughout the search no application of qualitative designs were found. Two studies used an experimental study design (randomized crossover trial) to obtain data and two described a prospective cohort study. The majority of papers $(n=11)$ were published in the period 2011-2015 and six in the preceding period up to and including 2010.

Seven articles concerned the application of AMTs, all of them devices with regard to at least respiratory support and/or nutritional support. Five studies used a nonexperimental quantitative design including the analysis of clinical data, such as record reviews or cohort studies, and two articles were reviews. Most articles on this subject $(n=5)$ were published in the period 2012-2015. 
Six articles described policy or management systems in different countries regarding the use of AMTs at home. The majority of the articles $(n=4)$ were in essay or review format. The other papers concerned a qualitative cross-sectional case study analysis and an observational quantitative study in which data are collected prospectively using a database. The categories of content will now be discussed in greater detail.

\section{Content description and trends to secondary research questions \\ User experiences}

In this category, 22 articles described the psychosocial impact on patients or informal caregivers from the use of medical technologies at home. Living at home with the assistance of medical technology needs a range of adjustments. Fex et al. [25, 26] state that self-care is more than mastering the technology, in terms of the health-illness transition, it requires '.... an active learning process of accepting, managing, adjusting and improving technology'. When it comes to children, they have to learn to incorporate disability, illness and technology actively within their process of growing up [27]. It seems that the use of medical technologies in the home can have both a positive and a negative psychosocial impact on patients and their families, which in turn causes ambivalence in experiences $[27,28]$. On the one hand, patients in general gain more independence, an enhanced overall health and a better quality of life [29-34]. On the other hand, for some patients the experience is one of dependency on others for executing daily activities, and these circumstances, to some extent, a social restricted live and perceived stigmatization [29, 30]. The situation in which patients need to use medical technology at home also affects family functioning and requires next of kin responsibilities [35-37]. As a result, next of kin caregivers are frequently faced with poor sleep quality and quantity, and/-or other significant psychosocial effects [38-41]. Nevertheless, family members had a positive attitude to the concept of bringing the technology into the home [42]. Knowledge of how to use the technology and permanent access to support from healthcare professionals and significant others, enabled next of kin caregivers to take responsibility for providing necessary care and to facilitate patients learning to provide selfcare $[25,36,42-44]$. Bezruczko et al. [45, 46] developed a measure of mothers' confidence to care for children assisted with medical technologies in their homes. To provide high quality sustainable care, nurses have to recognize and understand the psychosocial dimensions for both patients and family members which arise as a result of changing role and providing care for the patients. The need to provide emotional support and support with appropriate coping strategies is a key professional role [25, 26, 47]. Insight into the psychosocial effects on those involved can be used to assist designers of medical devices to find strategies to better facilitate the integration of these technologies into the home [28].

Seven articles reported on the usability, barriers and accessibility experienced by patients or informal caregivers. Findings in these studies showed that several technologies were rarely perceived as user-friendly and that home medical devices inadequately met the needs of individuals with physical or sensory deficits $[48,49]$. An accessible design which meets the diversity of individual user needs, characteristics and features would be better able to help patients manage their own treatment and so could contribute to the quality of care and safety of patients and lay users [50, 51]. Munck et al. [52] stated that restricted patients were reminded daily of the medical technology and were more dependent on assistance from healthcare professionals than masterful patients.

In contrast to the group of patients or informal caregivers, only two papers in this content category focused on the user experiences of nurses or other professional caregivers. The review demonstrates that to maintain patient safety, more education on application of medical devices for users is needed together with improved awareness and understanding of how to use the medical technology correctly in a patient-safe way $[53,54]$. More collaboration between all involved 'actors' in the process of care is also requisite. Continuity among carers, trust between patient and carers and supportive communication between informal and professional caregivers are important factors for the successful implementation of medical technologies in the home environment while maintaining patient safety $[44,51,53-55]$.

\section{Training, instruction and education}

Three articles regarding this topic focused on nurses or other professionals and four on the patients or informal caregivers. The results showed that successful use of advanced medical technologies at home requires adequate staff education and training programmes. Although many topics in educational programmes are suitable for different types of professionals in care provision, the focus for the level and application of information can vary for Registered Nurses and unregistered care staff. In addition, for overall learning experiences to be of maximum benefit there is a need for a clear focus on the specific client groups [56]. According to Sunwoo et al. [57], in the case of home non-invasive ventilation the degree of clinical support needed is extremely variable given the mixed indications for this respiratory support. A relatively simple procedure, such as the replacement of a feeding tube, can be performed by nurses, the patient and informal caregivers, provided they are trained 
well [58]. However, several studies revealed the complexity of the education needed by patients and informal caregivers for the use of advanced medical technologies at home $[59,60]$. Nevertheless, the studies revealed that a structured education programme, specific training, or the support of a dedicated discharge coordinator has several advantages $[59,61,62]$. It was evident that good preparation by patients or informal caregivers may result in a shorter length of stay in hospital, a better performance with regard to the use of the equipment or less requests by patients and/or families for assistance.

\section{Safety, risks, incidents and complications}

Most articles regarding this topic $(n=13)$ reported on safety in general, like aspects of safe use, factors affecting safety, complications and prevention of incidents in the home. Some identified the risk factors and the complications that may arise [63-65], where Stieglitz et al. [66] also emphasize that human error is the main reason for critical incidents and that regular instruction for medical staff and patients is necessary. To prevent untoward and adverse events, evidence based guidelines, recommendations on the preferred methods for managing the equipment, troubleshooting techniques for potential complications and monitoring activities are necessary [67, 68]. Faratro et al. [68] added that key performance and quality indicators are important mechanisms to ensure patient safety when using a medical device in the home. Methods to address or evaluate patient safety issues are for example, a home visit audit tool, a nationwide adverse event reporting system, programs such as the Medical Product Safety Network HomeNet, or, in the case of peripherally inserted central catheters (PICCs) a central catheter stabilization system [69-72]. However, a study conducted by Pourrat and Neuville [73] in France found that there are very few internal medical devices vigilance reports found within organizations that deliver devices for home parenteral nutrition and that safety management could be improved. The safe transfer of medical devices from a hospital setting to the home and vice versa, comes with several challenges regarding technological, environmental and human factors [14]. While many hospitals have developed policies to control the pathways of home-used devices in the hospitals, in case patients take them into the hospital when they are admitted for treatment [74]. Improvement of the safety of devices intended for use in home settings, implies also improvement of safety when their transfer to the hospital settings is urgently needed.

One article considered the technological factors, three the environmental and two the human factors. An example of research on the technological factors of safety related aspects of medical technologies used in home settings by Hilbers et al. [75] found that manufacturers pay insufficient attention to safety-related items in technical documentation for the use in the home setting. For instance, the environmental factor of electricity blackout leads to electrically powered medical devices failing. Studies show that this type of event causes a dramatic increase in appeal for access to emergency or hospital facilities, and that disaster preparation needs to include the specific needs of patients reliant on electrically driven devices [76-78]. Regarding human factors impacting on safety aspects, one article assessed the suitability of a particular theoretical framework for understanding safety-critical interactions of patients using medical devices in the home [79], while Tennankore et al. [80] described adverse events in home haemodialysis by the use of patients. It was remarkable that none of the articles focused on human factors with regard to the use of medical technologies at home by nurses or other professional caregivers.

\section{Design and technological development}

Of those articles that focused on this topic, ten reported on the comparison between different types of medical technologies, or their advantages and disadvantages. The comparison of different devices for oxygen therapy was made by two articles [81, 82] and one reported on the comparison of two types of enteral nutrition tubes [83]. Some studies regarding respiratory support considered the process of making a choice between different types of devices [84-86] while one paper considered the conditions for home-based haemo dialysis [87]. A minority, explored the individual characteristics and the clinical applications of several devices for respiratory support $[88,89]$ and one considered devices for insulin pump therapy [90]. Seven papers discussed the technological development or effectiveness of medical technologies. The testing of devices for external electro-stimulation was described in two papers [91, 92], with the testing of a new design patient lift was subject of one study [93]. Hanada and Kudou [94] explored the current status of electromagnetic interference with medical devices in the home setting, an issue of importance as more devices are considered for home use. The technological development of respiratory support for home use was part of one study [95], as were the possibilities of solar-assisted home haemo dialysis [96]. While the study by Pourtier [97] describes the advantages of analgesia pumps that can be read remotely by nurses, but also emphasizes the central position of a professional nurse in the transfer of information within a multi-disciplinary team.

\section{Application with regard to certain diseases or disorders, indications for and extent of use}

All articles described several aspects that need to be considered for use, such as clinical characteristics of the 
patients, indications for the use in the home setting, the technical availability of devices, the extent of their use at home or eventual complications and morbidity. It was important to note that all but one article $(n=6)$ were about children or related to adults with what are usually regarded as paediatric diseases. Results show that the use of AMTs at home among children after hospital discharge is common (in $20 \%-60 \%$ of cases), or is standard for patients with some disorders [98-101]. The timely application of advanced home medical technology benefits patients and can help to reduce respiratory morbidity [102]. Nevertheless, the rate of death of patients with Möbius syndrome using the devices at home was high (30\%) [98], as was that of patients with intestinal failure dependent on home parental nutrition therapy in Brazil (75\% for 5 years) [103]. The average cumulative survival of children needing home ventilation was found to be between 75 and 90\%, depending on the medical diagnosis [104].

\section{Policy and management}

Three of the papers were concerned with costs and/or reimbursement. The application of medical technologies in the home environment can be cost-effective when compared to institutionalized care $[22,105,106]$. Nevertheless, successful employment of medical technologies in the home necessitates medical guidelines for the indicators for use, careful identification of patients as well as careful planning and attention to details [105-107]. Two studies concerned the dilemma's for implementation of the technologies in home healthcare and emphasized the importance of cooperation in the chain of key stakeholders to maximize efficiency of high-tech healthcare at home, one with regard to the purchasing policy of medical technologies [108] and one with regard to the interventions of local community service centres and hospitals supporting optimal use of these technologies in the home setting [5].

\section{Discussion}

The use of medical technologies in the home setting has drawn increased attention in health care over the last 15 years, as the feasibility of this type of medical support has rapidly grown. This article systematically reviewed the international literature with regard to the state of the art on this subject, in order to provide a comprehensive overview.

Trend analysis over the period 2000-2015 shows that most research has been conducted about respiratory support, dialysis and oxygen therapy; relatively little about vacuum assisted wound closure and continuous passive motion, and no about decubitus treatment, skeletal traction and UV therapy. A substantial increase in publications was found in the period 2011-2015.
Although the number of studies on technologies is indicative of the extent to which they are used in home settings, however, no firm conclusions can be drawn about this.

This review also identified that most research is conducted with regard to 'user experiences' of medical technologies in the home, 'safety, risks, incidents and complications', and 'design and technological development of medical technologies'. There have been relatively few studies which have explored the topic of training, instruction and education. Content analysis showed that the use of AMTs in the home setting can have both a positive and a negative psychosocial impact on the patients and their families, and that it has become part of self-management and patient empowerment. Successful use of advanced equipment requires adequate education and training programmes for both patients, informal caregivers and nurses or other professionals. When trying to maximize or assure safety, technological, environmental and human factors have to be taken into account, and it is evident that human factors are the main reason for critical incidents. Studies on the design and technological development of medical technologies emphasize that research is necessary to improve its possibilities and effectiveness. The research found on the application of the technologies focused predominantly on children and the results indicate that the rate of the use of home medical devices among children after hospital discharge is common. Also that when compared to institutionalized care, the application of medical technologies in the home environment can be cost-effective. Much is known, but information on several key issues is limited or lacking.

An important finding was that in almost all the reviewed articles, the study subjects were patients or informal caregivers with very few studies focused on the role and activities of nurses or other professionals as users. This was unexpected as nurses are the main group of users of AMTs at home and they have to transfer knowledge and skills on how to use the devices to patients and other caregivers. Nurses also have a key role in setting up and maintaining collaboration between all actors involved in the process of care with regard to the use of home medical technologies and in giving support to patients and family members in this respect. There is need to initiate further in depth research on AMTs use at home focusing on the role of specifically nurses.

Another interesting result was that, despite the fact that most adverse events with AMTs at home are caused by human factors, hardly any studies conducted on this subject were found. None of the articles focused on related human factors regarding the use by nurses or other professional caregivers, although this is the main user group. Research on this area could contribute to improved patient safety and quality of care. The results also 
revealed the tension between the advantages and disadvantages of medical technologies as experienced by patients at home. Important aspects needed to promote the benefits include improving the user-friendliness of the devices and attuning their designs for the use in home settings. This emphasizes the importance of professionals (and patient groups) working together with the designers with regard to sharing knowledge and user experiences of the use of AMTs at home in order to improve quality of care and patient safety. This collaboration emerged as of key importance in the successful use of AMTs in the home as well.

Although all included articles were retrieved from academic databases and served our purpose, there was considerable heterogeneity of quality of the studies. Most of the studies have explicitly described their research design, albeit to a greater or lesser extent. On the other hand, there were a few studies that did not even mention their methodological approach, though it could be derived from the description. Most included reviews are of moderate quality. Although findings are almost always described clearly, the search strategy and selection criteria used are often lacking. The quantitative studies are generally well described in different methodological aspects, such as selection of respondents, research design, data collection methods and analyses. Studies of qualitative nature show more variation in the depth with which the design is described. However, almost all qualitative studies have described the research instruments very well, such as semi-structured interviews or questionnaires. Despite the varying quality of the studies, we believe that the whole of different methodological approaches and the relatively large number of included studies $(n=87)$ has yielded a fairly reliable overview on the international state of art concerning various aspects of the use of advanced medical technologies at home. For future research, we recommend to emphasize the development of a more detailed methodological design, zooming in on specific technologies, using large databases or conducting large surveys, and focusing on specific groups of respondents. Both in quantitative and in qualitative studies, a good definition of the research question(s), selection of respondents, development of instruments and analysis of findings, contributes to validity, consistency and neutrality.

Some limitations do have to be taken into account with this review. Although we used the RIVM-definition of 'advanced medical technology', not all devices are considered as 'complex devices' by nurses in practice. For example, the use of an anti-decubitus mattress in the context of 'decubitus treatment' and 'patient lifting hoists' are considered by nurses as being of less or lower complexity. However, overall the RIVM-classification was found to be a good starting point, and provided a practical and useful framework from which to work to gain an insight and overview of available medical technologies. Of some of the chosen technologies defined using the RIVM-classification of AMTs, questions do have to be asked as to whether they really are part of the technical skills in nursing process. For example, 'external electrostimulation' and 'continuous passive motion' are mainly applied by physiotherapists, although with appropriate training nurses can apply them. Then too, devices regarded as only 'monitoring' were excluded from the review.

\section{Conclusions}

This systematic review study was designed to fill a gap in the current research by investigating what is known about different aspects of medical technologies used in the home. From the results it is obvious that a wide and growing range of medical technologies are used at home. Different types of technologies have been subject of study, increasingly -also in scope- over the period 2011-2015.

Professional nurses have a central role in the process of homecare which has to be recognized when considering use of AMTs at home. Nurses have to support patients and family caregivers and in consequence have a key role in providing information for, and as a member of multi-disciplinary teams. Closer collaboration by all actors involved in the process of care and feedback of user experiences to the designers is essential for the provision of high quality of care and patient safety.

This review also identified a lack of research exploring the perspectives of nurses in the processes involved in introducing and maintaining technology in homecare. Most of the research has been conducted regarding the experiences of patient experience and how informal caregivers perceive their role in using medical technologies at home. The few studies that were found, demonstrate the need for more research focused on the experiences of nurses working with advanced technologies in the home. The same applies to research on training, instruction and education to use medical technologies, as in these areas too, there was limited available research so here again there is need for further research. Despite the fact that most adverse events with medical technologies in home settings are caused by human factors, our findings also identified a lack of research in this area for nurses.

This study demonstrates that, although there is increasing attention on and recognition of the need for the use of medical technologies in the environment of the home, the research has not kept pace with the advances in care. Subjects such as user experiences of nurses with different technologies, training, instruction and education of nurses and human factors by nurses in risk management and patient safety urgently need to be investigated by further research. 


\section{Abbreviations}

AED: Automatic external defibrillator; AMT: Advanced medical technology; CPAP: Continuous positive airway pressure; EC: European Commission; IT: Information technology; NCHS: National Center for Health Statistics; NPV: Negative pressure ventilation; PICCs: Peripherally inserted central catheters; RCT: Randomized Control Trial; RIVM: National Institute for Public Health and the Environment; UV: Ultraviolet; VAD: Ventricular assist device; WHO: World Health Organization

\section{Acknowledgements}

The authors thank Ronnie van de Riet, head of the Medical Technical Care Team of the hospital ZiekenhuisGroep Twente, for his time and commitment to this project.

\section{Funding}

Not applicable.

\section{Availability of data and materials}

The dataset generated and/or analyzed during the current study are available in Table 3 .

\section{Authors' contributions}

All authors meet the criteria for authorship and all those entitled to authorship are listed as authors. ITH made the conception and design of the study; acquisition, analysis and interpretation of data; and drafting the article. SBA and $\mathrm{WWH}$ have made substantial contributions to the conception and design of the study; the analysis and interpretation of data; and revising the article critically for important intellectual content. All authors have approved the final article, this submission and its publication.

\section{Author's information}

Ingrid ten Haken is researcher in the research group Technology, Health \& Care at Saxion University of Applied Sciences, Enschede, The Netherlands. Somaya Ben Allouch is head of the research group. Wim van Harten is professor at the University of Twente, Faculty Behavioural, Management and Social Sciences, department Health Technology \& Services Research and CEO of Rijnstate general hospital, Arnhem, The Netherlands.

\section{Ethics approval and consent to participate}

Not applicable.

\section{Consent for publication}

Not applicable.

\section{Competing interests}

The authors declare that they have no competing interests.

\section{Publisher's Note}

Springer Nature remains neutral with regard to jurisdictional claims in published maps and institutional affiliations.

\section{Author details}

'Saxion University of Applied Sciences, Research Group Technology, Health \& Care (TH\&C), P.O. Box 70.000, 7500 KB Enschede, The Netherlands. ${ }^{2}$ Department Health Technology \& Services Research (HTSR), University of Twente, Faculty Behavioural, Management and Social Sciences (BMS), Ravelijn 5246, P.O. Box 217, 7500 AE Enschede, The Netherlands. ${ }^{3}$ Rijnstate General Hospital, Arnhem, The Netherlands.

Received: 3 October 2017 Accepted: 26 January 2018 Published online: 26 February 2018

\section{References}

1. Hollestelle M, Hilbers E, van Tienhoven E, Geertsma R. Geavanceerde medische technologie in de thuissituatie: inventarisatie, gebruikersaantallen en risico's. RIVM rapport 265011004/2005. Rijksinstituut voor Volksgezondheid en Milieu RIVM, Bilthoven; 2005.

2. WHO. Primary Health Care. Now more than ever. World Health Organization, Geneva; 2008.

3. Arno P. Bonuck K. Padgung R. The economic impact of high-technology home care. Spec. Suppl. Hast Cent Rep. 1994;24:S15-9.
4. Arras J, Neveloff Dubler N. Bringing the hospital home: ethical and social implications of high tech home care. Spec. Suppl. Hast Cent Rep. 1994;24:S19-28.

5. Lehoux P, Charland C, Richard L, Pineault R, St-Arnaud J. Technologies de pointe et soins à domicile. Où en sont les CLSC? Can Med Assoc J. 2002;166:1277-8.

6. IGZ. Risico's van medische technologie onderschat. Staatstoezicht op de volksgezondheid, Den Haag; 2008.

7. Hilbers E, de Vries C, Geertsma R. Veiligheid van medische technologie in de thuissituatie. Een analyse op basis van onderzoek van technische dossiers van fabrikanten. RIVM Rapport 360050022/2009. Rijksinstituut voor Volksgezondheid en Milieu RIVM: Bilthoven; 2009.

8. WHO. WHO Global model regulatory framework for medical devices including IVDS. Draft for comment. World Health Organization, Geneva; 2016.

9. EC. Commission welcomes new agreement for safer use of medical devices. 2016 [cited 2016 June 29]: Available from:http://ec.europa.eu/growth/toolsdatabases/newsroom/cf/itemdetail.cfm?item_id=8863\&lang=en. 2016.

10. Council of the European Union. Proposal for a regulation of the European Parliament and of the council on medical devices, and amending directive 2001/ 83/EC, regulation (EC) no 178/2002 and regulation (EC) no 1223/2009. 2016.

11. NCHS. Health, United States, 2009. In Brief-Medical Technology [Internet]. National Center for Health Statistics, Hyattsville, M.D.; 2010. Available from: http://www.cdc.gov/nchs/data/hus/hus09_InBrief_MedicalTech.pdf

12. Weick-Brady MD, Lazerow RN. Medical devices: promoting a save migration into the home. Home Healthc Nurse. 2006;24:298-304.

13. Kaufman-Rivi D, Collins-Mitchell J, Jetley R. Design considerations for medical devices in the home environment. Biomed. Instrum. Technol. 2010; Home Health:21-6.

14. Fu M, Weick-Brady M, Tanno E. Medical devices in the home: a unique challenge for the FDA. Work. 2012:41:361-5.

15. Brady P. Creating home medical devices. When it comes to designing products for home healthcare, challenges are universal. Health Manag. Technol. 2011;May:32(5):17

16. Verkerke GJ, ten Cate Hoedemaker HO, Drost R, Pot JWGA, Lansbergen MDI, HM BCA, et al. Medische Technologie at risk? In: Onderzoek naar risico's bij medische technologie en mogelijkheden om deze te voorkomen of te reduceren. Onderzoeksrapportage in opdracht van het Ministerie voor Volksgezondheid, Welzijn en Sport. Onderz. Opdr. ven het Minist. voor Volksgezond. Welz. en Sport; 2011.

17. Sixtieth World Health Assembly. Health technologies [internet]. 2007. Available from: http://www.who.int/medical_devices/resolution_wha60_29-en1.pdf

18. FDA. What is a home use device? [cited 2016 June 29]: Available from: https://www.fda.gov/MedicalDevices/ProductsandMedicalProcedures/ HomeHealthandConsumer/HomeUseDevices/default.htm\#1.

19. Wagner J, Power E, Fox H. Technology dependent children: hospital versus home care. Philadelphia, PA: Office of Technology Assessment Task Force. JP; 1988.

20. OTA. Technology Dependent Children: Hospital v. Home Care. A Technical Memorandum (Report No. OTA-TM-H-38). US Government Printing Office Washington, DC; 1987. http://ota.fas.org/reports/8728.pdf

21. Hochstadt N, Yost D. In: Hochstadt N, Yost D, editors. The medically complex child: the transition to home care. Ann Arbor, Michigan: Harwood Academic Publishers, Bell \& Howell; 1991.

22. Lewarski JS, Current GPC. Issues in home mechanical ventilation. Chest. 2007;132:671-6

23. APSF. Definition and examples of advanced medical technology (AMT). [Internet]. 2016 [cited 2016 Jun 29]. Available from: http://www.apsf.org/ initiatives.php

24. Hessels J, de Vries C, Hilbers E, de Bruijn A, Geertsma R. Risico's bij gebruik van complexe medische technologie in de thuissituatie. Stand van zaken 2013. RIVM Rapport 2014-0061. Rijksinstituut voor Volksgezondheid en Milieu RIVM, Bilthoven; 2014

25. Fex A, Ek A-C, Söderhamn O. Self-care among persons using advanced medical technology at home. J Clin Nurs. 2009;18:2809-17.

26. Fex A, Flensner G, Ek A-C, Söderhamn O. Health-illness transition among persons using advanced medical technology at home. Scand J Caring Sci. 2011;25:253-61.

27. Kirk S. How children and young people construct and negotiate living with medical technology. Soc Sci Med Elsevier Ltd. 2010;71:1796-803.

28. Thomson R, Martin JL, Sharples S. The psychosocial impact of home use medical devices on the lives of older people: a qualitative study. BMC Health Serv Res. 2013:13:467-75.

29. Brooks D, King A, Tonack M, Simson H, Gould M, Goldstein R. User perspectives on issues that influence the quality of daily life of ventilator-assisted individuals with neuromuscular disorders. Can Respir J. 2004;11:547-54. 
30. Lehoux P, Saint-Arnaud J, Richard L. The use of technology at home: what patient manuals say and sell vs. what patients face and fear. Sociol Health IIIn. 2004:26:617-44.

31. Heaton J, Noyes J, Sloper P, Shah R. Families' experiences of caring for technology-dependent children: a temporal perspective. Health Soc Care Community. 2005;13:441-50.

32. Alsaleh FM, Smith FJ, Thompson R, Al-Saleh MA, KMG T. Insulin pump therapy: impact on the lives of children/young people with diabetes mellitus and their parents. Int J Clin Pharm. 2014;36:1023-30.

33. Bortolussi R, Zotti P, Conte M, Marson R, Polesel J, Colussi A, et al. Quality of life, pain perception, and distress correlated to ultrasound-guided peripherally inserted central venous catheters in palliative care patients in a home or hospice setting. J Pain Symptom Manag. 2015;50:118-23.

34. Gavish L, Barzilay Y, Koren C, Stern A, Weinrauch L, Novel FDJ. Continuous passive motion device for self-treatment of chronic lower back pain: a randomised controlled study. Physiotherapy. 2015;101:75-81.

35. Wang K-WK, Barnard A. Technology-dependent children and their families: a review. J Adv Nurs. 2004;45:36-46.

36. Munck B, Sandgren A, Fridlund B, Mårtensson J. Next-of-kin's conceptions of medical technology in palliative homecare. J Clin Nurs. 2012;21:1868-77.

37. Toly VB, Musil CM, Carl JC. Families with children who are technology dependent: normalization and family functioning. West J Nurs Res. 2012;34:52-71.

38. Glader LJ, Palfrey JS. Care of the child assisted by technology. Pediatr Rev. 2009;30:439-45

39. Keilty K, Cohen E, Ho M, Spalding K, Stremler R. Sleep disturbance in family caregivers of children who depend on medical technology: a systematic review. J Pediatr Rehabil Med. 2015;8:113-30.

40. Paddeu EM, Giganti F, Piumelli R, De Masi S, Filippi L, Viggiano MP, et al. Sleeping problems in mothers and fathers of patients suffering from congenital central hypoventilation syndrome. Sleep Breath. 2015;19:1057-64.

41. Toly VB, Musil CM, Zauszniewski JA. Resourcefulness training intervention: a promising approach to improve mental health of mothers with technologydependent children. Appl Nurs Res. 2014;27:87-90.

42. Fex A, Flensner G, Ek A-C, Söderhamn O. Living with an adult family member using advanced medical technology at home. Nurs Inq. 2011;18:336-47.

43. Fex A, Flensner G, Ek A-C, Söderhamn O. Self-care agency and perceived health among people using advanced medical technology at home. J Adv Nurs. 2012;68:806-15.

44. Craig GM, Scambler G, Spitz L. Why parents of children with neurodevelopmental disabilities requiring gastrostomy feeding need more support. Dev Med Child Neurol. 2003;45:183-8.

45. Bezruczko N, Chen SPC, Hill C, Chesniak JM. Fundamental measurement of functional caregiving in rehabiliation medicine. In: 19th IMEKO world Congr; 2009. p. 2115-22

46. Bezruczko N, Chen SPC, Hill CD, Chesniak JM. Measurement of mothers' confidence to care for children assisted with tracheostomy technology in family homes. J Appl Meas. 2011;12:339-57.

47. Kirk S, Glendinning C, Callery P. Parent or nurse? The experience of being the parent of a technology-dependent child. J Adv Nurs. 2005;51:456-64.

48. Lehoux P. Patients' perspectives on high-tech home care: a qualitative inquiry into the user-friendliness of four technologies. BMC Health Serv Res. 2004;4:1-9.

49. Fung $\mathrm{CH}$, Igodan U, Alessi C, Martin JL, Dzierzewski JM, Josephson K, et al. Human factors/usability barriers to home medical devices among individuals with disabling conditions: in-depth interviews with positive airway pressure device users. Disabil Health J. 2015;8:86-92.

50. Lemke MR, Mendonca RJ. A question of accessibility: understanding lay users of medical devices. Biomed Instrum Technol 2013;Spring:201:20-5.

51. Rajkomar A, Farrington K, Mayer A, Walker D, Blandford A. Patients' and carers' experiences of interacting with home haemodialysis technology: implications for quality and safety. BMC Nephrol. 2014;15:195.

52. Munck B, Sandgren A, Fridlund B, Mårtensson J. Patients' understanding of medical technology in palliative home care: a qualitative analysis. J Hosp Palliat Nurs. 2012;14:191-8.

53. Munck B, Fridlund B, Mårtensson J. District nurses' conceptions of medical technology in palliative homecare. J Nurs Manag. 2011;19:845-54.

54. Siewers V, Holmøy T, Frich JC. Experiences with using mechanical inexsufflation in amyotrophic lateral sclerosis. Eur J Phys. 2013;15:201-7.

55. Jayanti A, Wearden AJ, Morris J, Brenchley P, Abma I, Bayer S, et al. Barriers to successful implementation of care in home haemodialysis (BASIC-HHD):1. Study design, methods and rationale. BMC Nephrol. 2013;14:197.
56. Hewitt-Taylor J. Children who require long-term ventilation: staff education and training. Intensive Crit Care Nurs. 2004;20:93-102.

57. Sunwoo BY, Mulholland M, Rosen IM, Wolfe LF. The changing landscape of adult home noninvasive ventilation technology, use, and reimbursement in the united states. Chest. 2014;145:1134-40.

58. Fayemendy P, Sourisseau H, Jesus P, Desport JC. Changement de sonde de gastrostomie à ballonnet de l'adulte. Nutr Clin Metab. 2014;28:216-8.

59. Graf JM, Montagnino BA, Hueckel R, McPherson ML. Children with new tracheostomies: planning for family education and common impediments to discharge. Pediatr Pulmonol. 2008;43:788-94.

60. Wong J, Eakin J, Migram P, Cafazzo JA, Halifax NVD, Chan CT. Patients' experiences with learning a complex medical device for the self-administration of nocturnal home hemodialysis. Nephrol Nurs J. 2009;36:27-32.

61. Tearl DK, Cox TJ, Hospital HJH. Discharge of respiratory-technologydependent children: role of a dedicated respiratory care discharge coordinator. Respir Care. 2006;51:744-9.

62. dos Santos-Fontes RL, Ferreiro de Andrade KN, Sterr A. Conforto AB. Homebased nerve stimulation to enhance effects of motor training in patients in the chronic phase after stroke: a proof-of-principle study. Neurorehabil Neural Repair. 2013;27:483-90.

63. Buchman AL, Opilla M, Kwasny M, Diamantidis TG, Okamoto R. Risk factors for the development of catheter-related bloodstream infections in patients receiving home Parenteral nutrition. J Parenter Enter Nutr. 2014;38:744-9.

64. Davenport A. Complications of hemodialysis treatments due to dialysate contamination and composition errors. Hemodial Int. 2015; 19(Suppl 3):S30-3.

65. Szeinbach SL, Pauline J, Villa KF, Commerford SR, Collins A, Seoane-Vazquez E. Evaluating catheter complications and outcomes in patients receiving home parenteral nutrition. J Eval Clin Pract. 2015;21:153-9.

66. Stieglitz S, George S, Priegnitz C, Hagmeyer L, Randerath W. Life-threatening events in respiratory medicine: misconnections of invasive and non-invasive ventilators and interfaces. Pneumologie. 2013:67:228-32.

67. McGoldrick M. Preventing infections in patients using respiratory therapy equipment in the home. Home Healthc Nurse. 2010;28:212-20.

68. Faratro R, Jeffries J, Nesrallah GE, MacRae JM. The care and keeping of vascular access for home hemodialysis patients. Hemodial Int. 2015;19(Suppl 1):S80-92.

69. François K, Faratro R, d'Gama C, Wong E, Fung S, Chan CT. Utility of baseline home visit audit in home Hemodialysis. ASAIO J. 2015;61:695-700.

70. Kaufman-Rivi D, Hazlett AC, Hardy MA, Smith JM, Seid HB. Provider experiences with negative-pressure wound therapy systems. Adv Skin Wound Care. 2013;26:311-8.

71. Kaufman D, Weick-Brady M. Homenet: ensuring patient safety with medical device use in the home. Home Healthc Nurse. 2009;27:300-7.

72. Egan GM, Siskin GP, Weinmann R, Galloway MM. A prospective Postmarket study to evaluate the safety and efficacy of a new peripherally inserted central catheter stabilization system. J Infus Nurs. 2013;36:181-8.

73. Pourrat M, Neuville $\mathrm{S}$. Nutrition parentérale à domicile: prise en charge et suivi des incidents; mise en œuvre des vigilances. Enquête sur la France métropolitaine. Nutr Clin Metabolisme. 2007:21:109-14.

74. Tanno E. Policies and pathways of home-use medical devices through hospitals. J Clin Eng. 2010;35:215-22.

75. Hilbers ESM, de Vries CGJCA, Geertsma RE. Medical technology at home: safety-related items in technical documentation. Int J Technol Assess Health Care. 2013;29:20-6.

76. Nakayama T, Tanaka S, Uematsu M, Kikuchi A, Hino-Fukuyo N, Morimoto T, et al. Effect of a blackout in pediatric patients with home medical devices during the 2011 eastern Japan earthquake. Brain and Development. 2014;36:143-7.

77. Rand DA, Mener DJ, Lerner EB, DeRobertis N. The effect of an 18-hour electrical power outage on an urban emergency medical services system. Prehosp Emerg Care. 2005:9:391-7.

78. Greenwald PW, Rutherford AF, Green RA, Giglio J. Emergency department visits for home medical device failure during the 2003 North America blackout. Acad Emerg Med. 2004;11:786-9.

79. Rajkomar A, Mayer A, Blandford A. Understanding safety-critical interactions with a home medical device through distributed cognition. J Biomed Inform. 2015:56:179-94.

80. Tennankore KK, D'Gama C, Faratro R, Fung S, Wong E, Chan CT. Adverse technical events in home hemodialysis. Am J Kidney Dis. 2014;65(1):116-21.

81. Su C-L, Lee C-N, Chen H-C, Feng L-P, Lin H-W, Chiang L-L. Comparison of domiciliary oxygen using liquid oxygen and concentrator in northern Taiwan. J Formos Med Assoc. 2014;113:23-32. 
82. Paul J, Otvos T. Comparison of nasal cannulas and the OxyArm in patients requiring chronic domiciliary oxygen therapy. Can Respir J. 2006;13:421-6.

83. Ao P, Sebastianski M, Selvarajah V, Gramlich L. Comparison of complication rates, types, and average tube patency between jejunostomy tubes and percutaneous gastrostomy tubes in a regional home enteral nutrition support program. Nutr Clin Pract. 2015;30:393-7.

84. Leger SS. Humidification des voies aériennes lors de la ventilation à domicile. Rev Mal Respir. 2005;22:1065-70.

85. Gregoretti C, Navalesi P, Ghannadian S, Carlucci A, Pelosi P. Choosing a ventilator for home mechanical ventilation. Breathe. 2013;9:394-409.

86. Chatburn RL. Which ventilators and modes can be used to deliver noninvasive ventilation? Respir Care. 2009;54:85-101.

87. Farrington K, Greenwood R. Home haemodialysis: trends in technology. NDT Plus. 2011;4:iii23-4.

88. Scala R. Bi-level home ventilators for non invasive positive pressure ventilation. Monaldi Arch Chest Dis - Pulm Ser. 2004:213-21.

89. Khirani S, Louis B, Leroux K, Delord V, Fauroux B, Lofaso F. Harms of unintentional leaks during volume targeted pressure support ventilation. Respir Med. 2013;107:1021-9.

90. Kropff J, Del Favero S, Place J, Toffanin C, Visentin R, Monaro M, et al. 2 month evening and night closed-loop glucose control in patients with type 1 diabetes under free-living conditions: a randomised crossover trial. Lancet Diabetes Endocrinol. 2015;3:939-47.

91. Yik Yl, Ismail KA, Hutson JM, Southwell BR. Home transcutaneous electrical stimulation to treat children with slow-transit constipation. J Pediatr Surg. 2012:47:1285-90

92. Prenton S, Kenney LP, Stapleton C, Cooper G, Reeves ML, Heller BW, et al. Feasibility study of a take-home Array-based functional electrical stimulation system with automated setup for current functional electrical stimulation users with foot-drop. Arch Phys Med Rehabil. 2014;95:1870-7.

93. Bostelman R, Ryu J-C, Chang T, Johnson J, Agrawal SK. An advanced patient lift and transfer device for the home. J Med Device. 2010;4:11004.

94. Hanada E, Kudou T. Ensuring electromagnetic compatibility between medical devices and wireless communications and measures against electromagnetic noise. Trans Jpn Soc Med Biol Eng. 2014;52:OS-43-4.

95. Dubois P, Bérenger E. La ventilation à domicile. IRBM. 2009;30:258-61.

96. Agar JWM, Perkins A, Tjipto A. Solar-assisted hemodialysis. Clin J Am Soc Nephrol. 2012;7:310-4

97. Pourtier J. La technologie au service d'une meilleure prise en charge de la douleur au domicile. La Rev l'infirmière. 2013;190:36-8.

98. Matsui K, Kataoka A, Yamamoto A, Tanoue K, Kurosawa K, Shibasaki J, et al. Clinical characteristics and outcomes of Möbius syndrome in a children's hospital. Pediatr Neurol. 2014;51:781-9.

99. Feudtner C, Villareale NL, Morray B, Sharp V, Hays RM, Neff JM. Technologydependency among patients discharged from a children's hospital: a retrospective cohort study. BMC Pediatr. 2005;May 9;5(1):8.

100. Brown KA, Bertolizio G, Leone M, Dain SL. Home noninvasive ventilation: what does the anesthesiologist need to know? Anesthesiology. 2012;117:657-68.

101. Michihata N, Matsui H, Fushimi K, Yasunaga H. Clinical features of adult patients admitted to pediatric wards in Japan. J Adolesc Health. 2015:57:421-4.

102. Han YJ, Park JD, Lee B, Choi YH, Suh DI, Lim BC, et al. Home mechanical ventilation in childhood-onset hereditary neuromuscular diseases: 13 years' experience at a single center in Korea. PLoS One. 2015;10:e0122346.

103. Lee ADW, Galvao FHF, Dias MCG, Cruz ME, Marin M, Pedrol CN, et al. Home parenteral nutrition program and referral of potential candidates for intestinal and multivisceral transplantation in a single Brazilian center. Transplant Proc. 2014:46:1839-41.

104. Amin RS, Fitton CM. Tracheostomy and home ventilation in children. Semin Neonatol. 2003:8:127-35.

105. Southey D, Pullinger D, Loggos S, Kumari N, Lengyel E, Morgan I, et al. Discharge of thoracic patients on portable digital suction: is it cost-effective? Asian Cardiovasc Thorac Ann. 2015;23:832-8.

106. Hendrickson E, Corrigan ML. Navigating reimbursement for home parenteral nutrition. Nutr Clin Pract. 2013;28:566-71.

107. Weiler-Ravell D. The quandary of home-care respiratory management. Isr Med Assoc J. 2002;4:459-60.

108. Short D, Norwood J. Why is high-tech healthcare at home purchasing underdeveloped and what could be done to improve it? Health Serv Manag Res. 2003;16:127-35.

\section{Submit your next manuscript to BioMed Central and we will help you at every step:}

- We accept pre-submission inquiries

- Our selector tool helps you to find the most relevant journal

- We provide round the clock customer support

- Convenient online submission

- Thorough peer review

- Inclusion in PubMed and all major indexing services

- Maximum visibility for your research

Submit your manuscript at www.biomedcentral.com/submit
C) Biomed Central 